\title{
A Breath of Fresh Air \\ Abstracts from the 2009 Canadian Respiratory Conference
}

\author{
April 23-25, 2009 \\ Toronto, Ontario
}

\section{Exercise/Disease Self-Management Exercise/l'auto-prise en charge de la maladie}

1

FALLS AND BALANCE IN INDIVIDUALS WITH CHRONIC OBSTRUCTIVE PULMONARY DISEASE

Marla K Beauchamp ${ }^{1,2}$, Kylie Hill ${ }^{2}$, Roger S Goldstein ${ }^{2,3}$, Tania Janaudis-Ferreira, ${ }^{2}$ Dina Brooks ${ }^{1,2,4}$

${ }^{1}$ Graduate Department of Rehabilitation Science, University of Toronto, ${ }^{2}$ Respiratory Medicine, West Park Healthcare Centre, ${ }^{3}$ Departments of Medicine, ${ }^{4}$ Physical Therapy, University of Toronto, Toronto, Ontario

RATIONALE: Preliminary evidence suggests that individuals with COPD exhibit deficits in balance control. Further investigation of balance and risk of falls is warranted in these patients. The aim of the present study was to determine the clinical measures that discriminate fallers from nonfallers among individuals with COPD.

METHODS: A cross-sectional study design was used. Subjects $>60$ yrs with COPD attended a single assessment session. One-year incidence of falls was collected via self-report questionnaire. Functional balance was determined using the Berg Balance Scale (BBS), Timed Up and Go Test (TUG) and the Activity Specific Balance Confidence (ABC) Scale. Exercise tolerance and functional limitation were assessed using the SixMinute Walk Test (6MWT) and the MRC dyspnea scale, respectively. RESULTS: 39 COPD subjects $\left(\mathrm{FEV}_{1}=42 \pm 17 \%\right.$ predicted; age $71 \pm 7$ yrs $)$ completed the study. $46 \%(n=18)$ reported at least one fall in the preceding year. Statistically significant differences between fallers and non-fallers were found for the $\mathrm{ABC}(65.8 \pm 18.2$ vs. $81.7 \pm 11.1$; $\mathrm{p}=0.002)$, use of supplemental oxygen ( $72 \%$ vs. $24 \% ; \mathrm{p}=0.002)$, TUG $(17.0 \pm 4.9$ vs. $14.0 \pm 3.1$ seconds; $\mathrm{p}=0.024)$, BBS $(45.2 \pm 5.4$ vs. $48.8 \pm 5.0 ; \mathrm{p}=0.042$ ) and MRC (median 4, IQR 3 vs. median 3, IQR 2; $\mathrm{p}=0.046)$. Use of supplementary oxygen and balance confidence were independent predictors of falls $(\mathrm{p}=0.027 ; \mathrm{p}=0.033$, respectively).

CONCLUSIONS: Patients with COPD fall frequently. Standard clinical balance measures discriminate self-reported fallers from non-fallers. These observations draw attention to an important secondary impairment in COPD.

Financial Support: Canadian Respiratory Health Professionals (MB), Ontario Respiratory Care Society (MB), Canada Research Chair (DB).

\section{2}

"I WISHED THERE HAD BEEN ANOTHER WAY - BUT YOU KNOW, THERE'S NOT": FAMILY CAREGIVER EXPERIENCE OF TRANSITION TO MECHANICAL VENTILATION

Winn Briscoe $^{1}$, Roberta Woodgate ${ }^{2}$

${ }^{1}$ Nursing Instructor, Red River College of Applied Arts, Science and Technology (presenter); ${ }^{2}$ Associate Professor, Faculty of Nursing, University of Manitoba, Winnipeg, Manitoba

RATIONALE: Growing numbers of children and adults, with chronic neurological and respiratory disease, survive respiratory failure because of their use of long-term mechanical ventilation (LTMV) systems (Corbett, 1998; Nierman \& Nelson, 2002; Simonds, 2003). Lindahl et al (2005) assert that a "deep existential dimension involved in starting home ventilation" has yet to be adequately addressed. Especially lacking is an understanding of family caregivers' perceptions of their shared journey of transition to life with LTMV. In order to provide optimal care for this complex patient population, an awareness of both individual and family caregiver views and perspectives is required.

METHODS: This phenomenological study utilized in-depth audiorecorded interviews, transcription and interpretive analysis, as described by van Manen (1999), in order to detail the lived transition experiences of 11 ventilator users and seven family caregivers. This poster focuses on the experiences and assigned meanings of family caregivers.

RESULTS: Family caregivers provided rich description of: the insidious nature of symptom progression in chronic respiratory failure; the burden of communication and decision making during respiratory crisis; the paradox of gratitude for, and fear of "the machine", and their ongoing state of vigilance. Both direct and implied advice and recommendations for health care professionals, ventilator users and family caregivers is described.

CONCLUSION: Findings from this study enhance our understanding of both the benefits and burdens of ventilator treatment.

Funding: Winn Briscoe's Master of Nursing work was supported by a Canadian Respiratory Health Professional fellowship award.

\section{3}

DIAGNOSIS AND MANAGEMENT OF COPD: GAPS IN CARE AND OPPORTUNITIES FOR IMPROVEMENT

PG Camp, PD Pare, RD Levy

St Paul's Hospital, University of British Columbia, Vancouver, British Columbia

COPD self-management depends on effective partnerships between knowledgeable patients and health care teams dedicated to evidence-based practice. There is little information on how those with or at risk for COPD understand the disease and how they are managed by their health care team.

OBJECTIVES: a) to determine patients' knowledge of COPD pathophysiology and risk factors and b) to determine the reported use of spirometry, medications, and smoking cessation management, in COPD patients and those at high risk for developing the disease.

METHODS: We recruited 88 index cases with respirologist-diagnosed COPD (mean $\mathrm{FEV}_{1} \%$ predicted 35\%) and their 145 current or exsmoking siblings (mean $\mathrm{FEV}_{1} \%$ predicted $81 \%$ ) from the Vancouver site of a multi-centre study investigating genetics of COPD. Each individual underwent spirometry and a standardized interview. Questions queried exposure, symptoms, diagnosis, knowledge of pathophysiology of disease, smoking cessation management, medication use, and use of diagnostic tests. Knowledge of disease pathophysiology was scored (poor-excellent) by two independent raters.

RESULTS: Of the index cases (all with confirmed COPD), 83\% stated they had COPD, $7 \%$ stated they had asthma, and 10\% listed other conditions. Of those who stated they had COPD, $75 \%$ had a poor understanding of their condition. $80 \%$ of COPD index cases listed smoking as the cause of their condition. $17 \%$ of COPD index cases were still smoking but only $33 \%$ reported being offered prescription medications to aid quitting. $40 \%$ of the siblings stated they had respiratory symptoms and had reported their symptoms to their doctors but $25 \%$ had not received a diagnosis and $33 \%$ had not undergone spirometry. $92 \%$ of index cases were on medications, as were $71 \%$ of siblings with breathing problems.

CONCLUSION: COPD patients have a poor understanding of their disease and could benefit from improved education and more access to smoking cessation treatments. Spirometry is underutilized.

Funding: This study was supported by GlaxoSmithKline (U.S.A) and by an 
unrestricted educational grant from GlaxoSmithKline Canada Ltd. Dr Camp is currently supported by a CIHR Interdisciplinary Capacity Enhancement Team Grant - ICEBERGS.

4

\section{EFFECT ON HEALTH CARE COSTS OF AN ASTHMA EDUCATION INTERVENTION IN PRIMARY CARE}

Andrew Cave $^{1}$, Noreen Bhanji ${ }^{2}$, Colleen Makarowski ${ }^{1}$

${ }^{1}$ Department of Family Medicine; ${ }^{2}$ Faculty of Medicine, University of Alberta, Edmonton, Alberta

RATIONALE: Direct health care utilization costs (HCU) for asthma in Canada exceed $\$ 306$ million annually. We aimed to assess the impact on direct health care costs of asthma education delivered in the family physician's office.

METHODS: A site-randomised, unblinded controlled study of an educational intervention for asthma. 85 Family Physicians (FPs) in Alberta identified asthma patients from their billing data and invited them to participate. 250 asthma patients were screened and 200 were enrolled. Half of the practices were allocated to a control group for six months and half to the intervention. Both groups were assessed at 0,6 and 12 months. Those in the control group completed baseline spirometry, asthma evaluation and received an educational brochure. The intervention group received the same plus two hours (over three sessions) of one-on-one education from a certified asthma educator. Health care utilization in the preceding MONTH was assessed by the educator completing a form regarding urgent physician visits, emergency room attendance and hospital admission. The Edmonton Asthma Behaviour Scale (EABS), which is completed by the patient, also included a question on unplanned health care use over the last THREE MONTHS,

RESULTS: 58 subjects in the control group and 60 in the intervention group have completed six month assessments. Control group costs (by EABS scoring) fell from $\$ 115.6$ to $\$ 61.9$ per patient $(47 \%)$ and the intervention group costs fell from $\$ 178.2$ to $\$ 107.9$ per patient $(39 \%)$. Medication costs are not included.

CONCLUSIONS: Asthma assessment with spirometry and patient evaluation by a certified asthma educator in the FPs office can reduce direct health care costs for these patients

Financial Support: Was provided by Alberta Heritage Foundation for Medical Research, Alberta Strategy for The Management of Asthma (ASTHMA), Astra-Zeneca, GSK Canada, Nycomed and Boehringer Ingelheim.

\section{5}

VENTILATORY CONSTRAINT DURING ANAEROBIC AND CARDIOPULMONARY EXERCISE TESTS IN COPD AND HEALTHY CONTROLS

$\underline{\text { RL Chura }}^{1,2}{ }^{\text {, }}$ KB Earle1, JE Fortin ${ }^{1}$, JJ Koroll1, AE McManes ${ }^{1}$, MJ Walkner', DD Marciniuk ${ }^{2}$, SJ Butcher ${ }^{1,2}$

${ }^{1}$ Physical Therapy, University of Saskatchewan; ${ }^{2}$ Respirology, University of Saskatchewan, Saskatoon, Saskatchewan

RATIONALE: Cardiopulmonary exercise testing (CPET) reflects aerobic power and likely underestimates leg muscle anaerobic power in COPD. The Wingate anaerobic (WAT) and steep ramp (SR) tests have been proposed to reflect anaerobic power, but are not commonly used in COPD. The aim of this study was to compare SR, WAT and the CPET in both COPD and healthy populations.

METHODS: 9 subjects with COPD (FEV $146 \pm 16 \%$ pred, $72 \pm 3$ years) and 8 healthy elderly ( $67 \pm 6$ years) underwent CPET (increments of 5 to 15 watts/minute), SR (increments of 25 watts/10 seconds), and 30 second WAT tests on a cycle ergometer.

RESULTS: For both COPD patients and healthy subjects, the WAT mean work rate (WR) was greater than the peak WR on the CPET and SR; however, in COPD patients, SR peak WR was also greater than on the CPET. In the COPD group, similar peak exercise values were obtained between the SR, WAT, and CPET, respectively, for ventilation $(37,38$, $40 \mathrm{~L} \cdot \mathrm{min}^{-1}$ ), end-expiratory (EELV; 76, 77, 76 \% TLC), and end-inspiratory (EILV; 92, 93, 94 \%TLC) lung volumes, suggesting a similar level of ventilatory constraint between the tests not found in healthy controls. In the COPD group, high correlations were found between SR and the WAT WR $(\mathrm{r}=0.91)$ and between SR and CPET WR $(\mathrm{r}=.916)(\mathrm{p}<.001)$ Similarly, healthy controls had high correlations between SR and WAT WR $(r=.921)$ and between SR and CPET WR $(r=.987)(\mathrm{p}<0.001)$.

CONCLUSIONS: Differences in ventilatory constraint between the tests in the healthy controls reflect the different energy systems utilized. In contrast, the COPD group had a similar level of ventilatory constraint across all tests suggesting that, despite the higher WR in the anaerobic tests, patients exhibit ventilatory limitations similar to the more aerobic CPET.

Financial Support: Lung Association of Saskatchewan, University of Saskatchewan.

\section{6}

\section{ASTHMA ACTION PLANS (AAPS): VARIABILITY IN FORMAT} AND CONTENT

S Gupta ${ }^{1}$, FT Wan ${ }^{1}$, MD Lougheed ${ }^{2}$, MH Chignell ${ }^{1}$, SE Straus ${ }^{1}$

${ }^{1}$ University of Toronto, Toronto; ${ }^{2}$ Queen's University, Kingston, Ontario

INTRODUCTION: Written asthma action plan (AAPs) have been shown to improve clinically relevant outcomes in asthma, and their use is widely recommended. However, the ideal format and content of an AAP remains poorly defined, and several AAPs with differing format and content are currently in use. We sought to characterize the extent of variability in the format and content of existing AAPs.

METHODS: We completed a comprehensive search for AAPs from local/ national respiratory groups, asthma experts, and the internet. Two reviewers independently analyzed the format and content of each AAP.

RESULTS: We identified 47 unique AAPs from Canada (22), USA (19), Australia (3), UK (2), and unknown (1). Eighteen plans (38\%) were pediatric specific, and 29 (62\%) had no specifications. Results are summarized below.

\section{Format Features}

\begin{tabular}{llll}
\hline Layout (\%) & 3 zones (70) & 4 zones (17) & $\begin{array}{l}\text { Not zone-based } \\
\text { (13) }\end{array}$ \\
\hline Orientation (\%) & Landscape (34) & Portrait (66) & \\
Use of Images (\%) & Yes (43) & No (57) & \\
Use of Colour (\%) & Yes (70) & No (30) & \\
Narrative Format (\%) & 1st person (11) & 2nd person (72) & 3rd person (11) \\
\hline
\end{tabular}

\section{Content Features}

\begin{tabular}{|c|c|c|c|c|}
\hline $\begin{array}{l}\text { Peak Flow Cutoffs } \\
(\%)\end{array}$ & $\begin{array}{l}\text { Personal } \\
\text { best (47) }\end{array}$ & $\begin{array}{l}\text { Predicted } \\
\text { best }(2)\end{array}$ & $\begin{array}{l}\text { Blanks lines } \\
\text { only (32) }\end{array}$ & $\begin{array}{l}\text { Not included } \\
\text { (19) }\end{array}$ \\
\hline \multicolumn{5}{|c|}{ Yellow Zone Descriptors* } \\
\hline $\begin{array}{l}\text { Increased } \\
\text { Symptoms (\%) }\end{array}$ & $\begin{array}{r}\text { Shortness of } \\
\text { breath (34) }\end{array}$ & Cough (77) & Wheeze (64) & $\begin{array}{l}\text { Chest } \\
\text { Tightness } \\
(45)\end{array}$ \\
\hline Control Criteria (\%) & $\begin{array}{l}\text { Number of } \\
\text { days with } \\
\text { symptoms } \\
\text { (per week) } \\
\text { (13) }\end{array}$ & $\begin{array}{l}\text { Number of } \\
\text { nights with } \\
\text { symptoms } \\
\text { (per week) } \\
\text { (15) }\end{array}$ & $\begin{array}{l}\text { Limited } \\
\text { physical } \\
\text { activity (30) }\end{array}$ & $\begin{array}{l}\text { Absenteeism } \\
\text { (23) }\end{array}$ \\
\hline \multicolumn{5}{|c|}{ Yellow Zone Instructions* } \\
\hline $\begin{array}{l}\text { Reliever Change } \\
\text { Recommendation } \\
(\%)\end{array}$ & $\begin{array}{l}\text { Dose } \\
\text { change NS } \\
(61)\end{array}$ & $\begin{array}{l}\text { Specific } \\
\text { dose } \\
\text { increase } \\
(2)\end{array}$ & $\begin{array}{l}\text { Reliever } \\
\text { change not } \\
\text { mentioned } \\
(37)\end{array}$ & \\
\hline $\begin{array}{l}\text { Controller Change } \\
\text { Recommendation } \\
(\%)\end{array}$ & $\begin{array}{l}\text { Dose } \\
\text { change NS } \\
(46)\end{array}$ & $\begin{array}{l}\text { Specific } \\
\text { dose } \\
\text { increase } \\
(4)\end{array}$ & $\begin{array}{l}\text { Controller } \\
\text { change not } \\
\text { mentioned } \\
(50)\end{array}$ & $\begin{array}{r}\text { Oral Steroids } \\
\text { Added (47) }\end{array}$ \\
\hline
\end{tabular}

"descriptors/instructions provided in the "yellow zone" - the first zone that recommended a change in management. NS Not specified

CONCLUSIONS: AAP format and content are highly variable; this may influence usability and uptake. Best common elements might be established by examining the preferences of users, content experts (pulmonolo- 
gists, asthma educators), and format experts (human factors engineers). Financial Support: Bell University Labs, Li Ka Shing Knowledge Institute of St Michael's Hospital

\section{7}

FIELD-BASED WALK TESTS ELICIT SIMILAR END-TEST MEASURES OF HEART RATE AND OXYGEN UPTAKE AS INCREMENTAL CYCLE ERGOMETRY TESTS IN PATIENTS WITH COPD

Kylie Hill ${ }^{2,3}$, Lynda Woon ${ }^{3}$, Thomas E Dolmage ${ }^{3}$,

Roger Goldstein ${ }^{1,2,3}$, Dina Brooks ${ }^{2,3}$

Departments of ${ }^{1}$ Medicine and ${ }^{2}$ Physical Therapy, University of Toronto; ${ }^{3}$ West Park Healthcare Centre, Toronto, Ontario

RATIONALE: Walking-based protocols, including the 6-minute walk test (6MWT), incremental shuttle walk test (ISWT) and endurance shuttle walk test (ESWT), are used to assess exercise capacity in patients with COPD. It is unclear how the cardio-respiratory responses elicited during these tests relate to each other, and to those elicited during a ramp cycle ergometry test $(\mathrm{CET})$. This information is important in determining the relative physiological demands among exercise tests.

METHODS: 11 patients ( $\mathrm{FEV}_{1}=53 \pm 18 \%$ pred; 8 males) completed two 6MWTs, two ISWTs, two ESWTs and one CET on separate days. Using a portable gas analysis system, measurements of oxygen uptake $\left(\mathrm{VO}_{2}\right)$, minute ventilation $\left(\mathrm{V}_{\mathrm{E}}\right)$ and heart rate $(\mathrm{HR})$ were averaged over the last 20 seconds of each test. Arterial oxygen saturation $\left(\mathrm{SpO}_{2}\right)$ was measured on test completion using pulse oximetry.

RESULTS:

\begin{tabular}{lcccc} 
& 6MWT & ISWT & ESWT & CET \\
\hline $\mathrm{VO}_{2}(\mathrm{~L} / \mathrm{min})$ & $1.31 \pm 0.44$ & $1.18 \pm 0.41$ & $1.27 \pm 0.43$ & $1.28 \pm 0.46$ \\
$\mathrm{~V}_{\mathrm{E}}(\mathrm{L} / \mathrm{min})$ & $45.4 \pm 23.6^{*}$ & $44.2 \pm 20.9^{*}$ & $44.7 \pm 21.0^{*}$ & $50.5 \pm 25.7$ \\
$\mathrm{~V}_{\mathrm{E}} / \mathrm{MVV}(\%)$ & $97.0 \pm 27.7^{*}$ & $95.1 \pm 24.4^{*}$ & $96.6 \pm 29.1^{*}$ & $108.3 \pm 31.3$ \\
$\mathrm{HR}(\mathrm{bpm})$ & $121 \pm 18$ & $123 \pm 18$ & $126 \pm 19$ & $127 \pm 24$ \\
$\% \mathrm{HRmax}$ & $80 \pm 13$ & $81 \pm 13$ & $83 \pm 14$ & $84 \pm 17$ \\
$\mathrm{SpO}_{2}(\%)$ & $85 \pm 4^{*}$ & $86 \pm 4^{*}$ & $86 \pm 4^{*}$ & $93 \pm 3$ \\
\hline
\end{tabular}

Mean \pm SD; MVV Maximum voluntary ventilation; \%HRmax Percentage of estimated maximum heart rate ${ }^{*} p<0.05$ vs CET

CONCLUSIONS: Walking and cycle-based tests elicited similar HR and peak $\mathrm{VO}_{2}$ in patients with COPD indicating that field-based tests elicit similar cardiac and oxidative demands in these patients.

Financial support: Physicians Services' Incorporated Foundation.

\section{8}

LIVING WITH RESPIRATORY ILLNESS IN RURAL SASKATCHEWAN: A QUALITATIVE PILOT STUDY

Shelly Hutchinson ${ }^{1}$, Donna Goodridge ${ }^{2}$, Donna Wilson ${ }^{3}$

${ }^{1}$ Master of Nursing Student; ${ }^{2}$ Associate Professor, College of

Nursing, University of Saskatchewan, Saskatoon, Saskatchewan;

${ }^{3}$ Professor, Faculty of Nursing, University of Alberta, Edmonton,

Alberta

RATIONALE: The many challenges of living with a respiratory illness may be compounded by residing in a rural area. Decreased access to health services (including home care and pulmonary rehabilitation programs) within the community, closure of local hospitals and nursing homes, geographic isolation and significant travel time to larger centres for management are system factors that may contribute to the poorer health status of rural Canadians. The purpose of this pilot study was to explore health status and health care utilization in a sample of people living with respiratory illness in rural Saskatchewan.

METHODS: As part of a larger longitudinal mixed methods study, faceto-face, semi-structured interviews were conducted with eight individuals diagnosed with $\operatorname{COPD}(\mathrm{n}=6)$, asthma $(\mathrm{n}=1)$ or bronchiectasis $(\mathrm{n}=1)$ living in a rural Saskatchewan health region with no metropolitan influence. An interpretive descriptive approach was used to analyze the interview data. Main points and topics were identified, along with the themes that best illustrated the main points and topics. Raw data, field notes, and memos were retained to assist in providing an audit trail.
RESULTS: Five primary themes were identified: 1) Continuing with meaningful activities; 2) Understanding and responding to illnessrelated limitations; 3) Appreciating multiple community supports; 4) Comprehending disease specific knowledge; 5) Accessing health care in a timely manner.

CONCLUSIONS: The interpretive descriptive approach assisted in understanding not only the challenges, but also the unique adaptations, of individuals living with chronic respiratory disease in rural communities in Saskatchewan. The themes identified in this research will inform future research that compares self-management of rural and urban individuals who are living with respiratory disease.

Financial Support: We gratefully acknowledge the financial support received from a CIHR Interdisciplinary Capacity Enhancement Grant.

\section{9}

\section{CARDIORESPIRATORY RESPONSES TO AN INCREMENTAL UNSUPPORTED UPPER LIMB EXERCISE TEST IN PEOPLE WITH COPD}

Tania Janaudis-Ferreira' ${ }^{1,2}$, Kylie Hill1,3, Priscila Robles-Ribeiro', Marla Beauchamp ${ }^{1}$, Roger Goldstein ${ }^{1,3,4}$, Karin Wadell ${ }^{2}$, Dina Brooks ${ }^{1,3}$

${ }^{1}$ Respiratory Medicine, West Park Healthcare Centre; ${ }^{2}$ Department of Community Medicine and Rehabilitation, Umeå University, Sweden; Departments of ${ }^{3}$ Physical Therapy and ${ }^{4}$ Medicine, University of Toronto, Ontario

RATIONALE: The symptom-limited incremental unsupported upper limb exercise test (UULEX) assesses unsupported arm exercise capacity in patients with COPD. The object of this study was to describe cardiorespiratory responses and symptoms during this test in individuals with COPD. METHODS: Five patients with COPD ( 4 females, $77 \pm 23$ yrs; $\mathrm{FEV}_{1}=$ $37 \pm 10 \%)$ performed the UULEX wearing a portable gas analysis system. Measurements of minute ventilation (VE), oxygen uptake $\left(\mathrm{VO}_{2}\right)$ and heart rate (HR) were averaged over the final $20 \mathrm{sec}$ epoch of each minute. Dyspnea and arm fatigue were scored at every minute using the Borg scale. The test was performed with the patient sitting opposite a chart that indicated 8 target heights. A $200 \mathrm{~g}$ plastic bar was moved to the lowest height 30 times a minute, and thereafter the target height was incremented each minute. Further increments were achieved by using a heavier bar $(500 \mathrm{~g})$. RESULTS: The target height achieved ranged from 5-8 (median= 8); no patient progressed to a heavier bar. The cardiorespiratory variables and symptoms are summarized below.

\begin{tabular}{|lccccc|}
\hline & $\mathrm{HR}(\mathrm{bpm})$ & $\mathrm{VO}_{2}(\mathrm{ml} / \mathrm{min})$ & $\mathrm{VE}(\mathrm{l} / \mathrm{m})$ & Dyspnea & Arm Fatigue \\
\hline Warm-up & $88 \pm 17$ & $318.8 \pm 37.5$ & $11.13 \pm 2.4$ & $0.5 \pm 0.5$ & $1 \pm 0.5$ \\
End-level & $105 \pm 18$ & $611.2 \pm 29.3$ & $20.49 \pm 2.11$ & $3 \pm 3$ & $5 \pm 0.5$ \\
\hline Data are presented as mean $\pm \mathrm{SD}$ & & & \\
\hline
\end{tabular}

There was a general trend of a greater change in $\mathrm{VO}_{2}, \mathrm{HR}$ and $\mathrm{VE}$ between levels 6 and $8\left(\Delta \mathrm{VO}_{2}=185 \pm 64 \mathrm{ml} / \mathrm{min} ; \Delta \mathrm{HR}=13 \pm 2 \mathrm{bpm}\right.$; $\Delta \mathrm{VE}=6.5 \pm 3.6 \mathrm{~L} / \mathrm{min}$ ) compared to the increase seen between levels 1 and $5\left(\Delta \mathrm{VO}_{2}=74 \pm 45 \mathrm{ml} / \mathrm{min} ; \Delta \mathrm{HR}=5 \pm 5 \mathrm{bpm} ; \Delta \mathrm{VE}=3 \pm 2 \mathrm{~L} / \mathrm{min}\right)$. The test evoked greater arm fatigue $(\Delta=5 \pm 0.5)$ than dyspnea $(\Delta=3 \pm 3)$ $(\mathrm{P}=0.04)$.

CONCLUSIONS: Target heights below $90^{\circ}$ shoulder flexion evoke minimal cardiorespiratory response. It may be appropriate to set training intensities for unsupported upper limb exercise according to arm fatigue rather than dyspnea.

Financial Support: Ontario Thoracic Society, West Park Healthcare Centre Foundation and Canada research chair program.

\section{0}

\section{PERCEPTIONS OF ASTHMA EDUCATION AND ASTHMA CONTROL AMONG PATIENTS WITH SEVERE REFRACTORY ASTHMA}

C Ross ${ }^{1}$, G Low ${ }^{1}$, B Williams ${ }^{1}$, D Vethanayagam ${ }^{2}$

${ }^{1}$ University of Alberta, Faculty of Nursing; ${ }^{2}$ Faculty of Medicine and Dentistry, Edmonton, Alberta

Typically, $5-10 \%$ of people with asthma have severe refractory disease 
(SRA), this being poorly understood and difficult to control. Patients with SRA account for up to $50 \%$ of the total costs associated with asthma. Although asthma self-management education is beneficial to asthma patients in general, the unique educational needs of patients with SRA in particular are poorly understood. Given the literature reviewed to date, to our knowledge, there are no published Canadian studies on determining what would be most helpful in terms of education about self-management for patients with SRA. Nor is there published Canadian studies on examining perceptions of asthma control for patients with SRA. Knowing the needs of the SRA patient from their perspective begs attention and has much potential to help health professionals understand how to tailor education programs for SRA patients.

The purpose of this study was to augment our understanding about the unique educational needs of patients with SRA. More specifically, the intent was to examine the perceptions about asthma education, self-management and asthma control among adults with SRA.

METHOD: A qualitative approach using indepth interviews and fieldnotes was used to address the research questions. The sample was comprised of 8 adults with SRA who met the following criteria: age $\geq 18$ years; English speaking; a physiologic confirmed diagnosis of current asthma with or without co-existing chronic obstructive pulmonary disease; physician assessment and management within the context of an asthma clinic for a minimum of 6 months; severity classification by a respirologist and; received asthma education from a certified asthma educator or respirologist. Content analysis was used to manually identify salient themes.

RESULTS: The major themes that arose from this exploratory study and their implications in terms of further research will be put forward.

\section{1}

\section{IMPACT OF ASTHMA EDUCATION ON PATIENT QUALITY OF LIFE}

Andrew Cave ${ }^{1}$, $\underline{\text { Sheldon Spier }}^{2}$, Colleen Makarowski ${ }^{1}$, Elaheh Ahmadi ${ }^{1}$

${ }^{1}$ University of Alberta; ${ }^{2}$ Alberta Children's Hospital, Edmonton, Alberta

RATIONALE: Providing asthma education in the Family Physician's (FP) office expands the model of primary care in Canada and provides an expanded role for health professionals in the primary care team. Does it improve patient quality of life? Our objective was to evaluate the impact of asthma education in FP's offices on patient quality of life.

METHODS: In a site randomized, unblinded controlled study of education for asthma, 85 FPs from 29 practices identified asthma patients and invited them to participate. 250 asthma patients were screened and 200 were enrolled ( 35 children). Half the practices were allocated to a control group and half to the intervention. Both groups were assessed at 0, 6 and 12 months. Subjects in the control practices completed spirometry and baseline asthma assessments and received an educational brochure. The study group received an additional three sessions of one-to-one education (totaling two hours) from the educators. One of the outcomes assessed was quality of life using Juniper's Asthma Related Quality of Life Questionnaire.

RESULTS: Data for 128 adult subjects who completed the six months assessments shows improvements in quality of life for both groups. The intervention group, with extra teaching, shows a greater improvement but this is not statistically significant overall although some items of the 32 item questionnaire show significant differences.

CONCLUSIONS: Asthma assessment by certified educators which includes spirometry, and assessment of control, medication and health care use and quality of life, can improve quality of life for patients with asthma when provided in FP offices. Personalised, patient-centred education can add to this effect.

Financial Support: Provided by Alberta Heritage Foundation for Medical Research, Alberta Strategy for The Management of Asthma (ASTHMA), Astra-Zeneca, GSK Canada, Nycomed and Boehringer-Ingelheim.
12

CARDIORESPIRATORY RESPONSES TO THE 6 MINUTE WALK TEST: HEALTHY ADULTS VS. ADULTS WITH COPD Lisa Wickerson ${ }^{1}$, Kylie Hill1,2, Lynda Woon ${ }^{1}$, Roger Goldstein ${ }^{1,2,3}$, Tom Overend ${ }^{4}$, Dina Brooks ${ }^{1,2}$

${ }^{1}$ Respirology, West Park Healthcare Centre; ${ }^{2}$ Department of Physical Therapy; ${ }^{3}$ Department of Medicine, University of Toronto, Toronto; ${ }^{4}$ School of Physical Therapy, University of Western Ontario, London, Ontario

RATIONALE: The six-minute walk test (6MWT) is used to measure functional exercise capacity in chronic obstructive lung disease (COPD). Little is known about how responses to this test differ between healthy adults and adults with COPD.

OBJECTIVE: To compare; (i) six-minute walk distance (6MWD) and (ii) cardiorespiratory variables collected during the test in both groups.

METHODS: 6MWTs were conducted according to ATS guidelines. Variables collected using a portable metabolic gas analyzer $\left(\right.$ Cosmed $\left.\mathrm{K} 4 \mathrm{~b}^{2}\right)$ were averaged during the final 20 seconds of each test.

RESULTS: Measurements were obtained in 12 subjects with COPD (age $67 \pm 8 \mathrm{yr}, \mathrm{FEV}_{1} 53 \pm 18 \%$ predicted) and 17 healthy subjects (age $60 \pm 11 \mathrm{yr}$, $\mathrm{FEV}_{1} 96 \pm 10 \%$ predicted). Responses are summarized in the Table below.

\begin{tabular}{|c|c|c|c|c|c|c|c|}
\hline Group & $\begin{array}{l}\text { 6MWD } \\
(\mathrm{m})\end{array}$ & $\begin{array}{l}\mathrm{VO}_{2} \\
(\mathrm{~L} / \mathrm{min})\end{array}$ & $\begin{array}{l}\mathrm{V}_{\mathrm{E}} / \mathrm{MVV} \\
(\%)\end{array}$ & $\begin{array}{l}\text { Heart } \\
\text { rate } \\
\text { (\% max) }\end{array}$ & $\begin{array}{l}\mathrm{SpO}_{2} \\
(\%)\end{array}$ & $\begin{array}{l}\text { End-test } \\
\text { dyspnea } \\
(0-10)\end{array}$ & $\begin{array}{l}\text { End-test } \\
\text { leg fatigue } \\
(0-10)\end{array}$ \\
\hline$\overline{\text { COPD }}$ & $477 \pm 78^{*}$ & $1.3 \pm 0.4^{*}$ & $94 \pm 28^{*}$ & $82 \pm 14$ & $85 \pm 4^{*}$ & $4 \pm 1^{*}$ & $2 \pm 2$ \\
\hline Healthy & $638 \pm 81$ & $1.7 \pm 0.4$ & $52 \pm 15$ & $91 \pm 13$ & $97 \pm 2$ & $2 \pm 2$ & $1 \pm 2$ \\
\hline
\end{tabular}

*denotes $p<0.05$ vs. healthy adults

CONCLUSIONS: Compared with healthy adults, the subjects with COPD walked shorter distances and achieved lower rates of oxygen consumption, reflecting their ventilatory limitation to exercise. Walkingbased exercise evoked greater dyspnea, but similar leg fatigue suggesting that this exercise is more constrained by central rather than peripheral limitations in people with COPD.

Financial Support: ORCS and Physicians Services Incorporated Foundation.

\section{3} RELATIONSHIPS BETWEEN ENERGY EXPENDITURE AND
MEASUREMENTS OF EXERCISE CAPACITY IN PATIENTS
WITH CHRONIC OBSTRUCTIVE PULMONARY DISEASE WITH CHRONIC OBSTRUCTIVE PULMONARY
Kylie Hill $^{2,3}$, Lynda Woon
, Thomas E Dolmage Roger Goldstein 1,2,3, Dina Brooks 2,3

Departments of ${ }^{1}$ Medicine and ${ }^{2}$ Physical Therapy, University of Toronto; ${ }^{3}$ West Park Healthcare Centre, Toronto, Ontario RATIONALE: In patients with chronic obstructive pulmonary disease (COPD), measures of exercise capacity may reflect an individual's energy expenditure during daily life. We examined the relationships between average daily energy expenditure and: (i) six-minute walk distance (6MWD); (ii) six-minute walk work (product of 6MWD and body weight; 6MWW); (iii) incremental shuttle walk distance (ISWD); (iv) incremental shuttle walk work (product of ISWD and body weight; ISWW); (v) work done during an endurance shuttle walk test (product of time to exhaustion, walking speed and body weight; ESWW) and; (vi) maximum power achieved during cycle ergometry test (Pmax).

METHODS: On separate "test" days, subjects performed a total of two six-minute walk tests, two incremental shuttle walk tests, two endurance shuttle walk tests and one ramp cycle ergometry test. Over $3.8 \pm 1.3$ nontest days, measurements of energy expenditure were collected using the Sensewear Armband.

RESULTS: 14 subjects completed the study (age $66 \pm 6 \mathrm{yr}, \mathrm{FEV}_{1} 50 \pm 17 \%$ predicted). Average daily energy expenditure was related to $6 \mathrm{MWD}$ $(r=0.68 ; p=0.007)$, ISWD $(r=0.71 ; p=0.005)$ and $P \max (r=0.58$; $\mathrm{p}=0.031)$, but not ESWW $(r=0.37 ; \mathrm{p}=0.2)$. The strength of the relationship between energy expenditure and 6MWD and ISWD was strengthened when these variables were multiplied by body weight to reflect work $(6 \mathrm{MWW} ; \mathrm{r}=0.76 ; \mathrm{p}=0.001$ and ISWW; $r=0.78 ; \mathrm{p}=0.001)$.

CONCLUSIONS: Work done during the 6-minute walk test 
and incremental shuttle walk test accounted for approximately $60 \%$ of the variance in the measurement of average daily expenditure. These fieldbased walking tests are appropriate markers of energy expenditure during daily life.

Financial Support: Physicians Services' Incorporated Foundation.

\section{Airways/Clinical Epidemiology Voies respiratoires/épidémiologie clinique}

\section{4}

\section{LUNG VOLUME AND FLOW RATES: INTERACTION OF OBESITY AND RESPIRATORY MUSCLE STRENGTH}

F Al-Ghimlas, GL Jones, KJ Killian, NL Jones

McMaster University Medical Centre, Hamilton, Ontario

OBJECTIVE: BMI and respiratory muscle strength interact in contributing to lung volumes (VA, VC and FEV1); inspiratory and expiratory flow rates; and the capacity to breathe. This interaction was explored in 18,435 individuals (3369 normal, 1500 had exercise intolerance for miscellaneous reasons, 3435 had pulmonary disease, 5233 had cardiac disease and 4898 had cardiopulmonary disease). Of the total population $65 \%$ were male, all were over the age of 40 (mean \pm SD for age was $59 \pm 10.2$ ), and mean \pm SD for BMI was $28 \pm 4.7$.

METHODS: MANOVA was performed with patients classified based on BMI $(<20,20-25,25-30,30-35$ and $>35)$, MIP $(<30,30-60,60-100$ and $>100 \mathrm{cmH} 2 \mathrm{O})$, MEP $(<30,30-60,60-100$ and $>100 \mathrm{cmH} 2 \mathrm{O})$ and the summation of MIP and MEP classified into weak, below average, above average and strong.

RESULTS: Alveolar volume, vital capacity, maximal inspiratory and expiratory flow rates increased modestly from a BMI $<20$ to a BMI 25-30 declining modestly as BMI increased further. At any given BMI all volumes and flow rates increased substantially as respiratory muscle strength increased.

CONCLUSION: The capacity to breathe results from the maximum activity of the inspiratory muscles. The ventilation required to exercise relative to the maximum breathing capacity $(\mathrm{MBC})$ represents the stress on the system and is closely related to the intensity of dyspnea. Measurement of $\mathrm{MBC}$ in heart, lung and neuromuscular diseases can be approximated from a flow volume measurement.

\section{5}

\section{LIVING WITH COPD IN CANADA: PATIENT SELF- ASSESSMENT AND OBJECTIVE MEASURES OF DISEASE IMPACT}

Rick Hodder ${ }^{1}$, Paul Hernandez ${ }^{2}$, Meyer Balter ${ }^{3}$, Lean Bourbeau ${ }^{4}$ ${ }^{1}$ Respiratory Medicine, University of Ottawa, Ottawa, Ontario; ${ }^{2}$ Medicine, Dalhousie University, Halifax, Nova Scotia; ${ }^{3}$ Medicine, University of Toronto, Toronto, Ontario; ${ }^{4}$ Medicine, McGill University, Montreal, Quebec

BACKGROUND: Based on self-reporting of diagnoses made by health care professionals (HCPs), 4.4\% of Canadians - nearly 750,000 people have COPD, which was the 4th leading cause of death in 2003. Despite regular publication of Canadian Thoracic Society (CTS) COPD guidelines, surveys suggest that significant COPD care gaps remain in Canada. An important cause for these care gaps is poor patient knowledge or understanding of their symptoms, warning signs for an exacerbation and actions to be taken.

METHODS AND RESULTS: The impact of living with COPD in the Canadian context, was measured by a survey of 406 (approx. 50\% male) current $(29 \%)$ or former smoking COPD patients, aged 40-54 (20\%), 55-64 (29\%), 65-74 (24\%), 75+ years (28\%). Diagnosis duration ranged from $1-10$ years in $69 \%$ and $>10$ years in $23 \%$, with $80 \%$ recalling having spirometry at diagnosis. Patients tended to over estimate the symptomatic severity of their COPD when compared to objective assessment by MRC dyspnea grade.

In addition, $52 \%$ felt they were not in control and panic attacks were frequently reported $(51 \%)$. On average, patients required $2.2 \mathrm{ED}$ visits/year for COPD and 64\% wished they had more information on how to deal with exacerbations. Work-related limitations were reported by $54 \%$ of those able to work.

Most patients (77\%) felt that proper management would permit a full and active life, however, only $54 \%$ had heeded physician advice to exercise and only $16 \%$ had been referred for pulmonary rehabilitation. There was a perception that the general public was poorly informed about COPD, resulting in a public stigma against this disease.

\section{Perception of public stigma against COPD}

\begin{tabular}{ll}
\hline & $\begin{array}{l}\% \text { patients who strongly } \\
\text { agree or somewhat agree }\end{array}$ \\
\hline $\begin{array}{l}\text { Public education about COPD would decrease } \\
\text { stigma }\end{array}$ & $63 \%$ \\
COPD is correctly depicted by the media & $50 \%$ \\
The public is well-informed about COPD & $37 \%$ \\
\hline
\end{tabular}

Financial Support: The Canadian Lung Association through an unrestricted grant from GlaxoSmithKline Canada.

\section{6}

\section{CARDIOVASCULAR RISK FACTORS AND DISEASE IN SUBJECTS WITH ACUTE EXACERBATION OF COPD} Cheryl Lane, Jane Burns, Don Sin, Stephan F van Eeden Pacific Lung Health Centre, iCAPTURE Centre, St Paul's Hospital, Vancouver, British Columbia

RATIONALE: Chronic obstructive pulmonary disease (COPD) is a progressive inflammatory condition of the airways, pulmonary vessels and lung parenchyma. Population-based studies have shown that reduced lung function $\left(\mathrm{FEV}_{1}\right)$ associated with COPD is strongly associated with excess cardiovascular morbidity and mortality. For example, the Lung Health Study showed that a $10 \%$ decrement in $\mathrm{FEV}_{1}$ among COPD patients is associated with a $\sim 30 \%$ increase in the risk of deaths from cardiovascular diseases (CVD) such as thrombo-embolism, sudden death, arrhythmia, heart failure and stroke. Furthermore, acute exacerbations of COPD (AECOPD) have also been shown to be associated with a high morbidity and mortality in COPD subjects.

METHODS: In a retrospective study of subjects admitted with AECOPD to a tertiary hospital we determined the prevalence of 1) existing underlying cardiovascular diseases and 2) risk factors for cardiovascular disease. We also determined the relationship between these factors and severity of COPD, impact on length of hospital stay and readmission rate within the next 12 months of first documented admission.

RESULTS: The majority of subjects admitted with AECOPD had either severe or very severe COPD (average GOLD Stage 3.2 \pm 0.8 ). They also exhibited a number of risk factors for CVD $(2.08 \pm 0.79)$ with $32 \%$ showed a previous history or evidence of underlying CVD. Interestingly, there was an inverse relationship between the subjects' baseline $\mathrm{FEV}_{1}$ and underlying CVD $\left(\mathrm{r}^{2}=0.15, \mathrm{p}<0.02\right)$ with a trend to more CVD disease in COPD subjects with milder disease (GOLD Stage $1 \& 2$ ).

CONCLUSION: We conclude that underlying cardiovascular disease is common in subjects admitted for AECOPD and we speculate that cardiovascular disease could contribute to the morbidity and mortality associated with acute exacerbations of COPD.

Financial Support: Financed in part by an unrestricted grant from the British Columbia Lung Association.

\section{7}

COPD EPIDEMIOLOGY AND CO-MORBIDITY: A REGISTRYBASED ANALYSIS

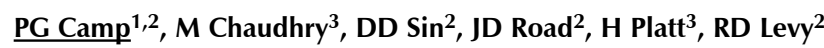

${ }_{1}$ Pharmaceutical Outcomes and Policy Innovations Programme; ${ }^{2}$ Respiratory Division, Department of Medicine, University of British Columbia; ${ }^{3}$ Ministry of Health Services, Government of British Columbia, Victoria, British Columbia

Administrative databases afford the opportunity to estimate populationbased COPD rates and outcomes. 
OBJECTIVE: To estimate the prevalence, mortality and hospitalization rates for COPD in British Columbia using administrative data and to determine the overlap of COPD diagnosis with asthma and congestive heart failure (CHF).

METHODS: Case definitions for COPD, CHF, and asthma were developed using ICD-9/10 codes on medical and hospital data. Individuals $>45$ years with at least 2 physician visits or one hospitalization for the specified ICD9/10 codes within 365 days were considered to be cases. Cases were ascertained from 1992 to 2004; prevalent cases in 2003/2004 were used for the analysis.

RESULTS: 73,857 people, or $4.3 \%$ of the over -45 years BC population, met the case definition for COPD. Older age groups had a much higher prevalence (up to $17 \%$ ). Men had a higher prevalence than women in all age groups. The relative rates for all-cause mortality among people with COPD in BC were 3-8 times higher than for people without COPD, with the highest relative rate (8-fold) for mortality in those aged 45-55. In $2003 / 2004,14 \%$ of COPD patients were hospitalized with respiratoryrelated illnesses. Up to $12 \%$ of those hospitalized cases were re-admitted within 2 weeks of discharge. $25 \%$ of COPD patients also met the case definition for CHF, while $11 \%$ of COPD patients were also in the asthma register.

CONCLUSION: COPD is highly prevalent and is associated with increased mortality, even in younger adults meeting the COPD case definition. The recognition of high rates of early re-hospitalization provides an opportunity for strategies which target improvement in transition care from hospital to the community. A large proportion of COPD patients also carry the diagnosis of asthma or CHF.

Financial Support: This study was funded by the Ministry of Health. Dr Camp is currently supported by a CIHR Interdisciplinary Capacity Enhancement Team Grant - ICEBERGS.

\section{8}

\section{RURAL AREAS BEAR THE BURDEN OF COPD: AN ADMINISTRATIVE DATA ANALYSIS}

PG Camp ${ }^{1,2}$, M Chaudhry ${ }^{3}$, DD Sin ${ }^{2}$, JD Road ${ }^{2}$, H Platt ${ }^{3}$, RD Levy ${ }^{2}$

${ }^{1}$ Pharmaceutical Outcomes and Policy Innovations Programme;

${ }^{2}$ Respiratory Division, Department of Medicine, University of

British Columbia; ${ }^{3}$ Ministry of Health Services, Government of

British Columbia, Victoria, British Columbia

Epidemiologists have predicted the prevalence of COPD in women will soon exceed that for men. Whether these predictions have been realized, or if these differences vary by geographic location is not known.

OBJECTIVE: We compared the prevalence of COPD in men and women in five geographic regions of British Columbia in 2003/2004. Each geographic region differed in terms of population density and rural versus urban settings.

METHODS: Case definitions for COPD were developed using ICD9/10 codes on medical and hospital data. Individuals $\geq 45$ years who had at least 2 physician visits or one hospitalization, for specified ICD9/10 codes, within 365 days were considered to be cases. Cases were ascertained from 1992-2004; prevalent cases in 2003/04 were used in the analysis.

RESULTS: In 2003/2004, men had a greater prevalence of COPD compared to women. However, the rural regions had the greatest prevalence of COPD for both men and women compared to the urban regions in the $65+$ age groups.
Prevalence (\%) of COPD by Health Region, Gender and Age, British Columbia, 2003/2004

Health Region

\begin{tabular}{cccccc} 
Age in Years & A Rural (\%) B Rural (\%) & C Mixed (\%) D Urban (\%) E Urban (\%) \\
\hline Women & & & & & \\
$45-54$ & 0.8 & 0.9 & 0.7 & 0.8 & 0.6 \\
$55-64$ & 3.4 & 3.5 & 2.9 & 2.6 & 2.2 \\
$65-74$ & 7.9 & 7.3 & 6 & 5.8 & 4.3 \\
$75-84$ & 13.2 & 11.1 & 9.6 & 9.1 & 7.5 \\
$85+$ & 15.5 & 12.2 & 11.2 & 10.1 & 10.3 \\
Men & & & & & \\
$45-54$ & 0.8 & 1.1 & 0.8 & 0.9 & 0.8 \\
$55-64$ & 3.6 & 4 & 3.1 & 3.2 & 2.8 \\
$65-74$ & 10.3 & 9.2 & 7.5 & 7.2 & 6.7 \\
$75-84$ & 18.6 & 16.1 & 13.5 & 12.5 & 9.1 \\
$85+$ & 24.4 & 20 & 16.4 & 15 & 15.7 \\
\hline
\end{tabular}

CONCLUSION: While COPD prevalence is still greater in men, older women in rural locations have a greater COPD prevalence than older men in urban locations. Rural regions bear the burden of COPD prevalence.

Funding: This study was funded by the Ministry of Health. Dr Camp is currently supported by a CIHR Interdisciplinary Capacity Enhancement Team Grant - ICEBERGS

\section{9}

\section{LIFE EXPECTANCY OF PARENTS WITH HEREDITARY HEMORRHAGIC TELANGIECTASIA IN A CANADIAN POPULATION}

CP Edwards, EM de Gussem, JJ Mager, CJJ Westermann,

ME Faughnan

Department of Medicine, St Michael's Hospital, Li Ka Shing Institute of Knowledge, University of Toronto, Toronto, Ontario;

St Antonius Hospital, Department of Pulmonology, Nieuwegein, the Netherlands

OBJECTIVE: Hereditary Hemorrhagic Telangiectasia (HHT) is an autosomal dominant disorder complicated by pulmonary and cerebral arteriovenous malformations (AVMs). These are known to cause life-threatening complications, preventable with appropriate screening and treatment. We hypothesize that those with untreated HHT should have lower life expectancy than those without HHT.

METHOD: 261 patients of the Toronto HHT Clinic with clinical or genetic diagnosis (and of most senior generation) were sent a questionnaire regarding their parents. The questionnaire asked patients to recount mortal status and if deceased, date of birth/death and cause of death. For the deceased parent with HHT, questions about screening and treatment of AVMs were asked.

RESULTS: Thirty-one/261 (12\%) patients reported no known affected parent. Of the 148/230 (65\%) completed questionnaires, 28 had parents' information recorded by a sibling and 7 had insufficient information. For 113 parents with HHT, mean life expectancy was 68.3 years (range 20.7-91.7, SD 14.9), compared to 76.6 years (range 31.7-103.0, SD 13.9) for 85 parents without HHT $(p<0.01)$. The remaining parents without HHT remain alive. In women, 66 parents with HHT had mean age at death of 67.5 years (range 20.7-89.2, SD 16.3), compared to 80.2 years (range 31.7-103.0, SD 13.8) in 28 parents without HHT ( $<<0.01$ ). In men, 47 parents with HHT had mean age at death of 71.1 years (range 30.0-91.7, SD12.6) compared to 71.8 years (range 33.4-87.6 SD 13.1) in 57 parents without HHT ( $\mathrm{p}=0.8)$. Approximately $15 \%$ of parents were known to have undergone some form of screening or treatment for organ AVMs.

CONCLUSIONS: Mean life expectancy is lower for parents with HHT, particularly in women with HHT. The reduced life expectancy may be due to preventable complications from organ AVMs as few were screened and/ or treated.

ACKNOWLEDGMENTS: Li Ka Shing Institute of Knowledge (MEF), St Michael's Hospital Summer Student Scholarship (CE). 


\section{0}

\section{HOW LONG CAN ASTHMA REMISSIONS LAST?}

Andrea Gershon ${ }^{1,2,3}$, Jun Guan ${ }^{1}$, Chengning Wang ${ }^{3}$, Teresa To ${ }^{1,2,3}$ ${ }^{1}$ Institute for Clinical Evaluative Sciences; ${ }^{2}$ University of Toronto; ${ }^{3}$ The Hospital For Sick Children, Toronto, Ontario

RATIONALE: Asthma is a variable disease that clinically can persist, resolve, or present any possible combination of remissions and relapses over time. If a patient with asthma stops seeking medical attention for their disease, it is not always certain if they are in remission or their disease has resolved. Knowing the distribution of durations of asthma remissions would improve our understanding of the natural history and epidemiology of asthma.

METHODS: Large, universal population-based health administrative databases were used to follow all individuals with asthma living in Ontario, Canada in 1993 longitudinally for 14 years. Any duration of time between consecutive asthma health services claims greater than 1 year was defined as a remission. Using survival analysis, the probability of individuals experiencing a remission equal to or longer than a given number of years was determined.

RESULTS: There were 618,458 individuals with asthma in 1993 who were followed for 14 years. Of these individuals, $34.7 \%$ never had a remission. In the remaining individuals, $78.3 \%$ experienced one or more remission longer than 2 years, $27.9 \%$ experienced one or more remission longer than 5 years, and $3.7 \%$ experienced one or more remission longer than 10 years. Trends in children $(<15$ years $)$ and adults did not differ significantly from the overall results.

CONCLUSIONS: Health administrative data can be used to characterize duration of remission experienced by individuals with asthma. A duration upper limit of 10 years appears to account for most remission in the population. These values may be used for population-based asthma surveillance, asthma epidemiology research and to guide clinical practice.

\section{1}

\section{COMPARISON OF TRADITIONAL AND NEW CANADIAN REFERENCE VALUES FOR INTERPRETATION OF PULMONARY FUNCTION TESTS}

\section{LC Goode $^{1,2}$, MB Stanbrook ${ }^{1,2}$}

${ }^{1}$ Asthma and Airway Centre, University Health Network; ${ }^{2}$ Division of Respirology, University of Toronto, Toronto, Ontario

RATIONALE: Reference values for PFT interpretation were derived from groups that may not represent the general population. We assessed the impact of applying newly established Canadian predicted values on detection of disease and classification of results.

METHODS: Pulmonary function test data from three academic hospitals in Toronto, Canada were interpreted using the Canadian prediction equations, as well as equations published by Crapo (1981, 1982), Knudson (1982), Morris (1976), Hankinson (1999), Quanjer (1993), and Goldman and Becklake (1959). Differences in the lower limit of normal (LLN) and in the classification of obstructive and restrictive abnormalities were studied.

RESULTS: We analyzed 71,951 spirometry and 41,140 body plethysmography measurements from 36,461 patients, representing all pulmonary function testing done from 1995 to 2005. The results for FEV1/FVC by the Canadian equations was significantly lower than predicted by Crapo and Knudson, and higher than predicted by Morris and Hankinson. The TLC predicted by the Canadian equations was higher than predicted by Crapo, Quanjer and Goldman and Becklake. The number of studies interpreted as showing obstructive disease varied widely from $23.5 \%$ using the Morris equation and $39.0 \%$ using the Canadian equation to $44.6 \%$ using the Crapo equation. The number of studies interpreted as showing restrictive disease varied from $58.2 \%$ using the Goldman and Becklake equation to $70.4 \%$ using the Canadian equation. Substantial variability was also noted in the classification of severity of obstructive and restrictive defects.

CONCLUSIONS: Interpretation of pulmonary function tests, including detection of disease and classification of severity, varies significantly depending on reference equations used. Reference equations derived from subjects who best represent the local population should be used.

\section{2}

\section{DEVELOPMENT OF QUALITY INDICATORS FOR END-OF- LIFE CARE IN COPD}

Donna Goodridge ${ }^{1}$, Darcy Marciniuk ${ }^{2}$, Dina Brooks ${ }^{3,4}$, Anne van Dam ${ }^{5}$, Shelly Hutchinson 6

${ }^{1}$ Associate Professor, College of Nursing; ${ }^{2}$ Professor, College of Medicine, University of Saskatchewan, Saskatoon, Saskatchewan; ${ }^{3}$ Associate Professor, Department of Physical Therapy, University of Toronto, Toronto, Ontario; ${ }^{4}$ Canada Research Chair, Rehabilitation in COPD; ${ }^{5} \mathrm{~A}$ /Director National Lung Health Framework, The Lung Association; ${ }^{6}$ Master of Nursing Student, College of Nursing, University of Saskatchewan, Saskatoon, Saskatchewan

RATIONALE: The need to provide high quality care at the end of life (EOL) for people with COPD is a growing need, both globally and in Canada. Performance measurement using quality indicators has been strongly advocated as a means to improve health care delivery and clinical outcomes.

METHODS: A modified three round Delphi approach was used to identify an initial set of quality indicators relating to $\mathrm{EOL}$ care for people with COPD. The expert panel was comprised of Canadian researchers and clinicians who had published or presented in the area of end of life care for respiratory patients in the previous five years. Round $1(n=23)$ consisted of open-ended responses to questions identified from an extensive literature review. Thematic analysis generated 109 indicators for which panel ratings were sought in Round $2(\mathrm{n}=21)$. Initial draft statements were generated through analysis of measures of central tendency and dispersion. In Round $3(n=20)$, participants were asked to indicate their level of agreement and to comment on how the statements might be altered to achieve their agreement. Finally, a national consensus meeting was held on November 22, 2008 to review and refine the draft statements and also to consider options for future research and quality improvement initiatives in this area.

RESULTS: Consensus statements were generated in the following areas: EOL care planning; anticipating the need for EOL care planning; preferred site of care; key services and initiatives to optimize care; use of selected interventions; the role of formal palliative care services. Priority quality indicators identified were: appropriate symptom management; continuity of care; informal caregiver burden and family satisfaction with care; and quality of life.

CONCLUSIONS: The Delphi methodology and consensus meeting approach allowed for the emergence of collective wisdom about future directions for evaluating care quality EOL care of persons with COPD. Financial Support: We gratefully acknowledge the financial support received from a CIHR Meetings, Planning and Dissemination Grant, the Canada Research Chair held by Brooks and the CIHR/RPP New Investigator Award held by Goodridge.

\section{3}

\section{SIZE AS WELL AS ANTISTATIC PROPERTIES IS IMPORTANT FOR OPTIMUM DELIVERY OF MEDICATION VIA VALVED HOLDING CHAMBERS (VHCS)}

Howard Harkness, MW Nagel, V Avvakoumova, H MacKay, R Ali, J Mitchell

Trudell Medical International, London, Ontario

RATIONALE: It is important to optimize delivery of medication from VHCs such that fine particle mass (FPM) representing the therapeutically beneficial portion of the emitted dose from the pressurized metered dose inhaler (pMDI) is close to that from the pMDI alone. Removal of electrostatic charge aids in achieving consistent FPM, but our hypothesis is that chamber volume is also important.

METHODS: Fine particle delivery $(<4.7 \mu \mathrm{m}$ aerodynamic diameter $)$ of albuterol (Ventolin ${ }^{\circledR}$-HFA, GSK Canada; $100 \mu \mathrm{g} /$ actuation albuterol base equivalent ex actuator) was determined via $149-\mathrm{ml}$ non-electrostatic VHCs (AeroChamber Plus ${ }^{\circledR}$ Girlz/Boyz*; Trudell Medical International, Canada) with mouthpiece ( $\mathrm{n}=5$ devices) using an Andersen 8-stage cascade impactor equipped with USP induction port in accordance with the methodology in CAN/CSA/Z2641-02:2008. The impactor was operated at 
28.3 $\mathrm{L} / \mathrm{min} \pm 5 \%$ and a 2 -second delay was interposed between pMDI actuation and the onset of sampling to simulate likely use by an uncoordinated patient. Comparative measurements were made with smaller $(110-\mathrm{ml})$ anti-static VHCs (Pocket Chamber ${ }^{\mathrm{TM}}$; Teleflex Medical, Durham, NC). Measurements of FPM ex pMDI alone (no delay) were also made to provide benchmark data.

RESULTS: The aerosol emitted from both VHC groups comprised more than $92 \%$ fine particles, compared with $45 \%$ fine particle fraction for the pMDI alone. FPM from the AeroChamber Plus ${ }^{\circledR}$ Girlz/Boyz VHCs (mean $\pm \mathrm{SD}$ ) was $37.7 \pm 3.4 \mu \mathrm{g}$, compared with $18.7 \pm 1.6 \mu \mathrm{g}$ from the Pocket Chamber $^{\mathrm{TM}} \mathrm{VHCs}$ and $34.8 \pm 1.4 \mu \mathrm{g}$ from the pMDI alone.

CONCLUSIONS: The larger volume of the AeroChamber Plus ${ }^{\circledR}$ Girlz/ Boyz VHC provided closer agreement in FPM to that from the pMDI alone. This finding is in agreement with Dolovich (Aerosol Sci Technol 1993;18(3):230-240), who reported a strong dependency of emitted medication mass on VHC volume below $150-\mathrm{ml}$. Clinicians should be aware of the need to match FPM ex pMDI as close as possible when prescribing VHCs.

Financial Support: Trudell Medical International.

\section{4}

\section{FAMILY PHYSICIANS' PREPAREDNESS TO MANAGE TUBERCULOSIS}

Andrew Cave', Alan Kaplan ${ }^{2}$, Mohammad Salehyar ${ }^{3}$,

Sasha Parameswaran ${ }^{1}$

${ }^{1}$ University of Alberta; ${ }^{2}$ North York Hospital; ${ }^{3}$ Faculty of Dentistry, University of Alberta, Edmonton, Alberta

RATIONALE: Studies in several countries indicate that frontline physicians are under-prepared for managing the increasing incidence of Tuberculosis (TB). No data is available for the situation in Canada. Our objective was to determine the preparedness of Family Physicians (FPs) in Canada to manage TB.

METHODS: We developed a two page survey from a review of questions asked in surveys in other countries and included some knowledge testing questions. Using the Family Physicians Airways Group of Canada's membership database we mailed the survey to 950 members. Responses were analysed for frequencies and simple comparisons using SPSS. Physicians' confidence to manage TB was compared to their knowledge as tested by the questionnaire.

RESULTS: 227 FPs responded (24\%), most were aged between 40 and 60 $(64 \%)$ and were in practice between 10 and 30 years (58\%). Reflecting the membership pattern, $72 \%$ of respondents were from Ontario. Management knowledge scores exceeded confidence levels for North American graduates but not for graduates of any other region. Physicians from British Columbia, Alberta and Ontario similarly knew more than they thought they did regarding managing TB with management scores being above $60 \%$ in all provinces. The respondents identified areas of knowledge deficiency and educational methods that they preferred. Correlation of confidence and management scores was low at $\mathrm{R} 2=0.18$.

CONCLUSIONS: FPs are generally confident about their ability to manage TB but their knowledge of management falls between 60 and $70 \%$ correct. This fits with data from other countries.

Financial Support: This study was supported by a grant from the Public Health Agency of Canada and in kind support from the Family Physicians Airways Group of Canada.

\section{5}

\section{QUANTIFICATION OF PULMONARY VENTILATION HETEROGENEITY IN SICKNESS AND HEALTH:} GENERATION OF HYPERPOLARIZED HELIUM-3 MAGNETIC RESONANCE IMAGING VENTILATION GRADIENT VECTOR MAPS

L Mathew ${ }^{1,2}$, M Kirby 1,2, H Ahmed ${ }^{1,2}$, AR Wheatley ${ }^{1}$, C Licskai ${ }^{3}$, N Paterson ${ }^{3}$, DG McCormack ${ }^{3}$, Grace Parraga ${ }^{1,2}$

$1_{\text {Imaging Research Laboratories, Robarts Research Institute; }}$

${ }^{2}$ Department of Medical Biophysics; ${ }^{3}$ Division of Respirology, Department of Medicine, The University of Western Ontario, London, Ontario

RATIONALE: Respiratory diseases that involve the small airways including both chronic obstructive pulmonary disease (COPD) and asthma show changes in regional ventilation. Our objective was to develop a method to characterize the magnitude and direction of ventilation gradients to quantify airway remodeling over time, in response to therapies and for a better understanding of how changes in resistance and compliance effect pulmonary ventilation.

METHODS: MRI was performed on a whole body $3.0 \mathrm{~T}$ Excite $12.0 \mathrm{MRS}$ system with broadband imaging capability to obtain multi-slice ${ }^{1} \mathrm{H}$ and ${ }^{3} \mathrm{He}$ coronal images. ${ }^{3} \mathrm{He}$ multi-slice images were obtained in the coronal plane with centric $\mathrm{k}$-space sampling. All scanning was completed within approximately 7 minutes of subjects lying in the scanner. Doses of hyperpolarized ${ }^{3} \mathrm{He}(5 \mathrm{ml} / \mathrm{kg})$ were delivered in $1 \mathrm{~L}$ plastic bags diluted with ultrahigh purity, medical grade nitrogen so that the total volume of gas inhaled for each subject was $1 \mathrm{~L}$ from functional residual capacity. ${ }^{1} \mathrm{H}$ and ${ }^{3} \mathrm{He} \mathrm{MR}$ ventilation images for eight subjects with COPD, six age-matched healthy volunteers and seven younger subjects with asthma were evaluated for ventilation defect volume (VDV) and ventilation defect percent (VDP).

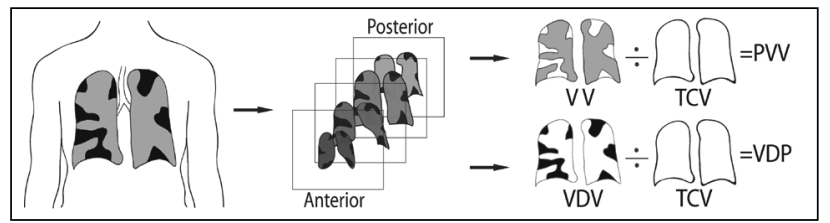

Figure 1. Coronal ${ }^{3} \mathrm{He}$ MRI segmentation for ventilation defect percent (VDP) and percent ventilation volume (PVV).

In addition, a gradient method was developed as described in equations 1 and 2 and applied to static coronal ${ }^{3} \mathrm{He}$ MR images of all subjects to provide the magnitude of the ventilation gradients $\left(\mathrm{V}_{\mathrm{G}}\right)$ in all $3 \times 3$ pixel regions of interest $(\mathrm{ROI})$ across the center coronal slice.

$$
\begin{aligned}
& V_{G x}(i, j)=\Delta\left(a_{i+1, j+1}+a_{i+1, j}+a_{i+1, j-1}-a_{i-1, j+1}-a_{i-1, j}-a_{i-1, j-1}\right) \\
& V_{G y}(i, j)={ }^{\Delta}\left(a_{i+1, j+1}+a_{i, j+1}+a_{i-1, j+1}-a_{i+1, j-1}-a_{i, j-1}-a_{i-1, j-1}\right)
\end{aligned}
$$

RESULTS: Coronal Center Slice Ventilation defects (VDV, VDP) and heterogeneity $\left(\mathrm{V}_{\mathrm{G}}\right)$ are provided in Table 1 .

\section{TABLE 1}

\begin{tabular}{lccr}
\hline & $\begin{array}{c}\text { Elderly Healthy } \\
\text { Volunteers (n=6) }\end{array}$ & Asthma (n=7) & COPD (n=8) \\
\hline VDV (SD) ml & $31(14)$ & $37(51)$ & $148(88)$ \\
VDP (SD) \% & $5(2)$ & $7(8)$ & $25(13)$ \\
$V_{G}(S D) \times 10^{7} \mathrm{~cm}^{-1}$ & $6.9(2.0)$ & $14.0(4.0)$ & $7.2(1.5)$ \\
\hline
\end{tabular}

CONCLUSIONS: In COPD, VDV and VDP are significantly increased compared to healthy elderly volunteers and younger patients with asthma whereas ${ }^{3} \mathrm{He}$ MRI $\mathrm{V}_{\mathrm{G}}$ is significantly greater in asthma as compared to healthy elderly and COPD patients.

Financial Support: Ontario Thoracic Society. 
26

USE OF ADMINISTRATIVE DATA FOR THE SURVEILLANCE OF ASTHMA AND COPD IN CANADA

Louise McRae ${ }^{1}$, Bob Prosser², Pat Camp², Larry Svenson ${ }^{3}$, Robert Campbell ${ }^{4}$, Niko Yiannakoulias ${ }^{5}$, Drona Rasali ${ }^{6}$, William Osei $^{6}$, Janice Hawkey ${ }^{6}$, Andrea Gershon ${ }^{7}$, Chengning Wang ${ }^{8}$, Teresa To $^{8}$, Mark Smith ${ }^{9}$ ${ }^{1}$ Chronic Disease Surveillance Division, Public Health Agency of Canada; ${ }^{2}$ Children's \& Women's Health Centre of BC; ${ }^{3}$ Alberta Health and Wellness; ${ }^{4}$ Concordia University College of Alberta; ${ }^{5}$ McMaster University; ${ }^{6}$ Saskatchewan Health; ${ }^{7}$ University of Toronto; ${ }^{8}$ Toronto Hospital for Sick Children; ${ }^{9}$ Dalhousie University Other advisors: Yue Chen, University of Ottawa; Nancy Garvey, Ontario Ministry of Health and Long-Term Care; Helena Klomp, Health Quality Council, Saskatchewan; Anita Kozyrskyj, Manitoba Centre for Health Policy

RATIONALE: A uniform approach to surveillance of chronic respiratory diseases in Canada is currently lacking. Collaborating with multiple provinces, the Public Health Agency of Canada is assessing the feasibility of using provincial health administrative data to create a surveillance system for major chronic respiratory diseases.

METHODS: Five provinces (Alberta, British Columbia, Nova Scotia, Ontario, Saskatchewan) convened in 2007 to design the feasibility study. Working definitions for asthma and COPD were established. Variations of the definitions across provinces were allowed depending on the availability of data. Three major health administrative databases were used: physician claims, hospital discharge abstracts, and provincial client registry. Prevalence of asthma and COPD were calculated and results were stratified by age groups and gender and compared across provinces.

RESULTS: Compared to the self-reported estimates from Statistics Canada's Canadian Community Health Survey (CCHS) the overall annual treated asthma prevalence rates in the 5 participating provinces were lower. This may be due in part to our case definition which was based on health services encounters; individuals with mild asthma or those that did not require a health service were not captured. On the other hand, provinces that measured cumulative prevalence may overestimate prevalence, by including resolved and/or false-positive cases.

The overall annual treated COPD prevalence rates were consistent with the self-reported estimates in the CCHS. In Ontario, physicians do not use ICD-490 (unspecified bronchitis) for billing, which may account for the lower COPD prevalence compared to other provinces. The provinces that provided cumulative prevalence estimates had estimates that were almost double the self-reported estimates.

CONCLUSIONS: Our results demonstrated the feasibility of using provincial administrative health data to generate comparable estimates of asthma and COPD across provinces. The results can provide a useful, acceptable, reliable and stable source of data for surveillance of treated asthma and COPD.

\section{7}

\section{GENDER AND AGE DISTRIBUTION OF PATIENTS WITH PULMONARY NONTUBERCULOUS MYCOBACTERIAL INFECTION IN ONTARIO}

$\underline{\text { Mauli Mehta }}^{2}$, Frances Jamieson ${ }^{2,3}$, Pamela Chedore ${ }^{4}$, Kevin May ${ }^{4}$, Mohammed Al Houqani ${ }^{1,2}$, Theodore K Marras ${ }^{1,2}$

${ }^{1}$ Division of Respirology, University Health Network and Mount Sinai Hospital, Department of Medicine; ${ }^{2}$ University of Toronto; ${ }^{3}$ Clinical and Environmental Microbiology, Public Health

Laboratories Branch; ${ }^{4}$ TB and Mycobacteriology Laboratory, Public Health Laboratories Branch, Ontario Ministry of Health and LongTerm Care, Toronto, Ontario

INTRODUCTION: Most studies of pulmonary nontuberculous mycobacterial (NTM) infection describe a male predominance. However, the American Thoracic Society (ATS) guidelines state that NTM infection is more common in females, citing studies excluding patients with underlying lung disease or immunosuppression. We studied gender and age in an unselected population with pulmonary NTM, and reviewed data regarding colonization versus disease.
METHODS: Age, gender and microbiologic criteria were determined for all patients in Ontario with a pulmonary NTM isolate in 2003 - "Ontario cohort". In an overlapping sample, we reviewed records of all patients with a pulmonary NTM isolate in 2002-3 who had records at the University Health Network, Toronto - "UHN cohort". NTM disease was defined according to ATS criteria.

RESULTS: Of 1755 patients in the Ontario cohort, 1026 (58\%) had M. avium complex (MAC), and 475 (27\%) had M. xenopi (mean [sd] age 63 [18] years, $48 \%$ female). Microbiologic criteria were fulfilled by $46 \%$ (age 65 [17] years, 51\% female). So, in the Ontario cohort, women comprised a very slight majority among those meeting ATS microbiologic disease criteria. Among 1408 patients in the UHN cohort, 858 (61\%) had MAC, and 383 (27\%) had M. xenopi (age 63 [17] years, 49\% female). Complete data regarding NTM disease were available for 276/1408 (20\%) in the UHN cohort - 131/276 (47\%) had disease (age was 64 [15] years, $58 \%$ [76/131] female). So, in the UHN cohort, women comprised the majority of those meeting all ATS disease criteria.

CONCLUSION: Although men comprised a very slight majority among all patients with an NTM isolate, men were less likely to have "disease". In an unselected population women comprised the majority with pulmonary NTM disease, supporting the notion that pulmonary NTM has become a female predominant illness.

\section{8}

\section{MECHANISMS OF OPIOID-INDUCED RESPIRATORY DEPRESSION IN ADULT RATS IN-VIVO}

Gaspard Montandon, Richard L Horner University of Toronto, Toronto, Ontario

RATIONALE: Respiratory rhythm is generated by pre-Bötzinger Complex (PBC) neurons in-vitro, with destruction of $\mathrm{PBC}$ neurons producing ataxic breathing in-vivo. Activation of $\mu$-opioid receptors at the $\mathrm{PBC}$ decreases respiratory rate in neonatal rats in-vitro, but the role of the $\mathrm{PBC}$ in opioidinduced respiratory depression has not been tested in-vivo.

METHODS: We recorded diaphragm and genioglossus (GG) muscle activities in adult rats with drugs applied to the PBC region by microdialysis probes.

RESULTS: In anesthetized rats $(n=6)$, application of the $\mu$-opioid receptor agonist fentanyl $(100 \mu \mathrm{M})$ to the PBC decreased respiratory rate (mean $=43 \%, \mathrm{p}=0.004)$ and GG activity (mean $=61 \%, \mathrm{p}=0.007$ ), with this depression reversed by the antagonist naloxone $(100 \mu \mathrm{M})$. The time delay for fentanyl-induced respiratory depression was correlated with the distance of the probe site from the PBC $\left(\mathrm{r}^{2}=0.83\right)$. Preliminary data in 2 freely behaving rats showed that fentanyl $(150 \mu \mathrm{M})$ at the PBC also reduced respiratory rate in non-REM sleep $(\sim 30 \%)$ but not wakefulness $(\sim 3 \%)$. The respiratory rate depression produced by fentanyl at the PBC also occurred with subcutaneous fentanyl $(0.02-0.1 \mathrm{mg} / \mathrm{kg})$ in anesthetized and freely behaving rats (mean decreases $30-54 \%, \mathrm{p}<0.05$ ).

CONCLUSION: These data show that opioid-sensitive neurons in the PBC mediate suppression of respiratory rate in-vivo, with responses to $\mu$-opioid receptor agonists being prominent in non-REM sleep and anesthesia.

Financial Support: GM was supported by the Canadian Lung Association Postdoctoral Fellowship Award. Research was supported by the Ontario Thoracic Society and CIHR.

\section{9}

SUSPECTED EXPOSURES REPORTED TO A WORK-RELATED ASTHMA SURVEILLANCE SYSTEM IN ONTARIO

Teresa To

Child Health Evaluative Sciences, The Hospital for Sick Children, Toronto, Ontario

RATIONALE: Asthma is the most frequent type of work-related lung disease. Currently there isn't a surveillance system in Ontario that captures and monitors prevalent cases of work-related asthma. The Ontario WorkRelated Asthma Surveillance System: Physician Reporting Network (OWRAS Network) was established to test the feasibility of a voluntary reporting system in which physicians in Ontario report cases of workrelated asthma seen in their practice. 
METHODS: Respirologists, occupational medicine physicians, allergists and general practitioners in Ontario were approached to participate in the OWRAS Network which involves monthly reporting of cases of occupational (OA) and work-aggravated asthma (WAA). A case is reported when it meets the following three criteria: a) a physician diagnosis of asthma; b) an association between symptoms of asthma and work (i.e., a particular job or process or work-related exposure); and c) exposure to an agent previously associated with asthma or evidence of an association between work exposure and either a significant decrease in lung function or increase in airways responsiveness. Reporting is done by phone, mail or electronically by email.

RESULTS: To date, 43 physicians are participating by reporting cases on a regular basis. Since 2007, 12 OA and 19 WAA cases have been reported. The following figure summarizes suspected exposures reported to the OWRAS Network.

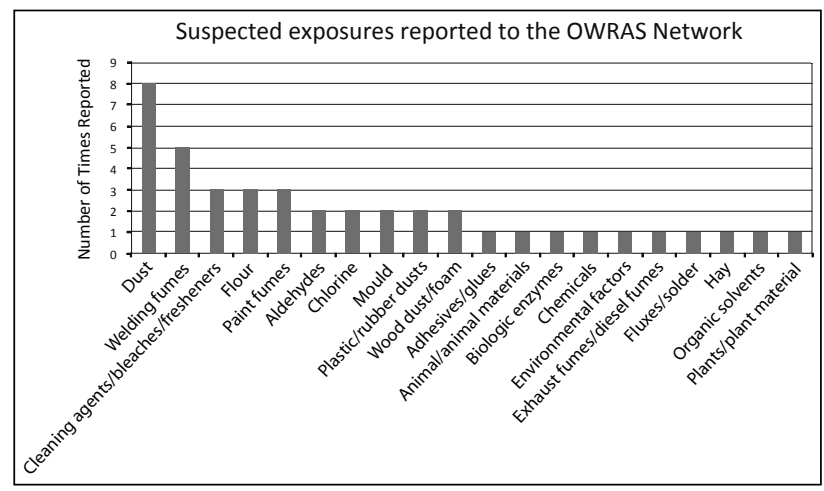

CONCLUSION: The OWRAS Network is a feasible voluntary reporting system for work-related asthma, in which physicians can report information on exposure, incidence and prevalence of $\mathrm{OA}$ and WAA. In future, the information collected may assist us in generating surveillance data that can be translated into usable information for public health action and support evidence-based policy and decision.

Financial Support: This study was supported by a grant from the Government of Ontario under the Asthma Plan of Action initiative.

\section{0}

\section{AIRWAY PHYSIOLOGY AND CELLULAR INFLAMMATION TO FRAGRANCE EXPOSURE IN ASTHMA: A PILOT STUDY DP Vethanayagam ${ }^{1}$, H Vliagoftis ${ }^{1}$, N Prasad ${ }^{2}$, L Smith ${ }^{3}$, CJ Jeng ${ }^{2}$, R Rogers $^{2}$, $\mathrm{R}$ Moqbel $^{4}$ \\ ${ }^{1}$ University of Alberta; ${ }^{2}$ Toxcon Health Sciences Research Centre Inc., Edmonton, Alberta, ${ }^{3}$ Research Institute for Fragrance Materials, United States; ${ }^{4}$ University of Manitoba, Winnipeg, Manitoba}

RATIONALE: Asthmatics often perceive fragrances affect their airways, yet there are no objective measurements that would support this assertion. Some information exists on the dermal effects of exposure to fragrance materials (De Groot et al, 1997; Bickers et al, 2003), however little information exists on inhalation exposure to these substances and what does exist suggests that inhalation is a minor route of systemic exposure (Cadby et al, 2002). A 1991 survey (Wallace et al, 1991) identified several classes of polar Volatile Organic Compounds (VOCs) in the airborne emissions of such products, including alcohols, esters, and aldehydes. It is estimated that there are over 3000 organic materials used in the manufacture of personal and home care products.

RESEARCH QUESTION: Does exposure to commonly used fragrance materials cause changes in airway physiology as assessed by spirometry? Does exposure to common fragrances cause airway inflammation as assessed by sputum cell counts?

METHODS: Randomized, double blind, placebo controlled crossover design. Eligibility screening involved physiologic confirmation of asthma (pulmonary function tests, reversibility testing and methacholine challenge if needed to establish "current asthma"). Clinical review by an asthma specialist (DV, HV) was performed including determination of clinical stability to proceed with the exposures. Subjects underwent ENT, dermal patch testing and allergen skin tests. Subjects were exposed in a $14 \mathrm{~m}^{3}$ challenge chamber to a surrogate pressurized fragrance product containing 9 fragrances* commonly found in household products such as air fresheners on 4 occasions ( 15 or 30 minutes of control [CS] or test substance [TS]), minimum of 2 week washout between exposures. Spirometry was done prior to and 3 hours following each exposure, and sputum induction done 3 hours following exposure.

RESULTS: Following ethics approval by the University of Alberta Research Ethics Board, complete exposure data was available from 12 nonasthmatics ( 6 atopic $-4 \mathrm{~F} / 2 \mathrm{M}), 12$ mild asthmatics (all atopic) and 8 moderate asthmatics $(7$ atopic $-3 \mathrm{M} / 4 \mathrm{~F})$. Fragrance related symptoms were noted by history in $1 / 2$ of the atopic non-asthmatics $(2 \mathrm{~F} / 1 \mathrm{M}), 1 / 3$ of the mild atopic asthmatics $(2 \mathrm{~F} / 2 \mathrm{M}$ ) and 3 moderate asthmatics (all female one non-atopic). Lung function as assessed by spirometry showed no change post TS exposure. Additionally, no change was noted in cellular airway inflammation overall, although a non-significant trend toward increased neutrophils was noted in only the moderate asthma group.

DISCUSSION: No significant adverse effects were noted in airway physiology or cellular inflammation was noted in the 3 respiratory groups studied. Due to the small sample size for this pilot study and overall variation in data range within all groups, further study is suggested with particular focus on severe asthmatics would be useful.

ACKNOWLEDGEMENTS: E James, D Pawluski, N Skjodt, I Mayers, J Beach, A Cave, D Krebs-Elaschuk Mah.

Financial Support: The Research Institute for Fragrance Materials, Inc. There was no involvement by the sponsor in study conduct, data entry, statistical analysis or interpretation.

*Fragrance materials chosen: D-limonene, Linalool, Benzyl Acetate, Hydroxycitronellal, Eugenol, $\beta$-Ionone, Methyldihydrojasmonate, Hexylcinnamicaldehyde, and HHCB.

\section{Pediatrics} Pédiatrie

\section{1}

\section{SCHOOL CHILDREN WITH ASTHMA PREDOMINANTLY USE CONTROLLER MEDICATIONS INTERMITTENTLY}

Harutai Kamalaporn ${ }^{1}$, Richard Foty ${ }^{1}$, Teresa To ${ }^{1}$, David Stieb ${ }^{2}$, Sharon Dell ${ }^{1}$

${ }^{1}$ The Hospital for Sick Children, University of Toronto, Toronto, Ontario; ${ }^{2}$ Health Canada, Canada

RATIONALE: While the Canadian Pediatric Asthma Consensus Guidelines emphasize the use of inhaled corticosteroid therapy early and regularly, poor asthma control remains prevalent in Canadian children. We studied whether asthma medications and devices were used appropriately, according to guidelines, in school-aged children with asthma in Toronto. METHODS: This study used data from the Toronto Child Health Evaluation Questionnaire, a population based survey that included 5619 grades one and two school children (age 5-9 years) from 231 schools in 2006. Asthma was defined as parental report of the child ever having asthma diagnosed by a physician. Prescribed medication use in the past 12 months was reported using a chart that included color pictures of all labeled asthma medications and devices in Canada. Each medication and device was characterized into either "regular daily use" or "intermittent use". Children with asthma were categorized into 3 severity groups based on reported symptoms: I) moderate to severe, II) mild, and III) asymptomatic. Percent distributions of use of medications and devices among these groups were compared using the chi-square statistic.

RESULTS: 847 parents reported that their children had asthma and $69 \%$ of them reported medication use. Among them, $86 \%$ reported using at least 1 controller, $79 \%$ used inhaled corticosteroids (ICS), $12 \%$ used combination of beta- 2 agonists/steroids, and $10 \%$ used leukotriene inhibitors (LTI). Controller medications were used in $84 \%, 62 \%$ and $22 \%$ of children in group I, II and III respectively. However, only a fraction of these children reported using ICS on a daily basis $(18 \%, 7 \%$ and $2 \%$ respectively, $\mathrm{p}<0.001$ ) and even a smaller proportion of them reported using the 
appropriate spacer device along with MDI (13\%, 3\%, 0.6\% respectively, $\mathrm{p}<0.001)$.

CONCLUSIONS: Most Toronto school children with asthma are using controller medications and spacer devices inappropriately.

Financial Support: Health Canada

\section{2}

SP-D COUNTERACTS GM-CSF-MEDIATED GRANULOMA FORMATION BY ALVEOLAR MACROPHAGES IN LYSINURIC PROTEIN INTOLERANCE

David N Douda ${ }^{1,3}$, Nicole Farmakovski ${ }^{1}$, Sharon Dell ${ }^{2}$, Hartmut Grasemann ${ }^{1,2}$, Nades Palaniyar ${ }^{1,3,4}$

${ }^{1}$ Lung Innate Immunity Research, Program in Physiology and Experimental Medicine, SickKids Research Institute; ${ }^{2}$ Division of Respiratory Medicine, SickKids; ${ }^{3}$ Department of Laboratory Medicine and Pathobiology, Faculty of Medicine, University of Toronto, Toronto, Ontario

RATIONALE: Pulmonary Alveolar Proteinosis (PAP) is a lung disease with multiple etiologies and is often deadly in Lysinuric Protein Intolerance (LPI). At present, PAP is treated with granulocyte/monocyte colony stimulating factor (GM-CSF) or by whole lung lavage; however, the effectiveness of GM-CSF in treating LPI PAP is unknown. We hypothesized that GM-CSF and surfactant protein D (SP-D) would enhance the clearance of proteins and dying cells that are typically present in the PAP lungs.

METHODS: Bronchoalveolar lavage fluid (BALF) from a two-year-old LPI patient was obtained. Protein levels were then analyzed using BCA protein assay and western blot was performed for SP-D and SP-A. BALF from an age-matched patient with an unknown airway disease was used as control. Oil Red O staining was performed on cytospin preparations. The cells and surfactant lipid were analyzed by TEM. Alexa-647 conjugated BSA or DiI-labelled apoptotic Jurkat T-cells was added to the cells in the presence or absence of SP-D $(1 \mu \mathrm{g} / \mathrm{ml})$ and/or GM-CSF $(10 \mathrm{ng} / \mathrm{ml})$ for phagocytosis assay. The images were analyzed by fluorescence microscopy. RESULTS: Here we show that the bioavailability of SP-D is low in PAP lungs. SP-D was partially degraded and entrapped in the unusual surfactant lipid with circular lattice structures, in vivo. We also show that supplementing SP-D and GM-CSF increase the uptake of protein and dying cells by LPI AMs, ex vivo. Serendipitously, we found that the LPI AMs spontaneously generated granulomas. Treating these cells with GM-CSF drastically increased the number of granulomas whereas SP-D treatment counteracted the adverse effect of GM-CSF.

CONCLUSION: We propose that increased GM-CSF and decreased bioavailability of SP-D promote granuloma formation and lower lung function in LPI lungs. Therefore, GM-CSF may not be suitable for treating PAP in LPI.

Financial Support: This project was funded by SickKids Foundation (NP) and CIHR (NP). DND is a recipient of SickKids' Restracomp/OSOTF scholarship.

\section{3}

\section{TRACHEOESOPHAGEAL FISTULA CARE AT THE ALBERTA CHILDREN'S HOSPITAL: PAST, PRESENT AND FUTURE}

L Fairservice, LS Schultz, M Bailey, C Bjornson, I Mitchell The Alberta Children's Hospital, Alberta Health Services, Faculty of Medicine University of Calgary, Calgary, Alberta

The Tracheoesophageal Fistula (TEF) Clinic at the Alberta Children's Hospital $(\mathrm{ACH})$ is a unique clinic in Canada. A retrospective data review of 18 children with TEF, surgically repaired at ACH from 1994-1999 revealed numerous inpatient admissions and high healthcare needs that involved multiple programs. Coordination of services was recommended to enhance family centred care.

The first clinic began in the spring of 2005. The clinic operates one half day per month with $4-5$ children seen per clinic by a multidisciplinary team. All newly diagnosed infants are seen within 1-2 months and then an average of 6 visits up until 2 years of age. Toddlers and older children are seen yearly. Seventeen new cases have been seen since 2005. Thirty children are followed in the clinic.

Analysis of this population reveals that the majority of these children have oesophageal atresia with a distal TEF (type C). Sixteen children (53\%) were born premature at $<37$ weeks gestation, $8(26 \%)$ have been diagnosed with VACTERL Syndrome, $3(0.1 \%)$ have other syndromes. There are 5 sets of twins $(17 \%)$.

TEF is not a simple "fixable" congenital abnormality. Gastroesophageal reflux, oesophageal dysmotility and stricture formation impact feeding and growth and require management of texture progression by the occupational therapist and dietician. Tracheomalacia complicates childhood respiratory illness, necessitating management by Respirology. The general paediatrician provides education, support and a specialized plan of care to the family and community physician. General surgery provides regular consultation to the clinic. The nurse clinician is the key contact for families. Early identification, team collaboration, family education / support and coordination of care are essential for the provision of high quality multidisciplinary care.

Future directions for the clinic include improved integration/involvement during hospitalization; establishing family connections, improved family education, and expansion of the clinic to include older children.

\section{4}

\section{GENDER - A FACTOR IN SMOKING AMONG BRITISH COLUMBIAN ADOLESCENTS: A COMPARISON STUDY BETWEEN ASTHMATICS AND NON-ASTHMATICS}

$\underline{\text { SE Guo }}^{1}$, JL Johnson ${ }^{2}$

${ }^{1}$ School of Nursing, University of Victoria, Victoria; ${ }^{2}$ Centre for Nursing and Health Behavior Research, School of Nursing, University of British Columbia, Vancouver, British Columbia

RATIONALE: Smoking is especially harmful to individuals affected by asthma. Little is known about gender differences in smoking among British Columbian adolescents with asthma, yet adolescent girls are more vulnerable than boys to smoking's impact on lung function. The aim of this study is to examine the prevalence of smoking and the relation between smoking and asthma with particular attention to gender differences.

METHODS: A provincial cross-sectional survey on the health status and smoking of adolescents was conducted in 2004 in secondary schools: 617 adolescents with asthma (defined as self-reported asthma that has required a prescription in the last 12 months) and 6903 adolescents without asthma. Multinomial logistic regression analyses was used to examine the relationship between asthma status and gender differences in smoking patterns (current smoker, former smoker, and ex-smoker) and controlled for other risk factors, such as age, ethnicity, grade, rating grade achievement, family financial situation, parents' smoking, friend's smoking, marijuana use, environmental tobacco smoke (ETS) exposure, alcohol use, perceived physical health, exercise frequency, and BMI were collected as covariates.

RESULTS: Adolescent girls with asthma were nearly twice as likely to smoke currently as adolescent boys without asthma (OR: 1.71; 95\% CI: 1.07-2.75). Asthmatic boys less likely to smoke than non-asthmatic boys (OR: 0.40; 95\% CI: 0.19-0.82). More adolescent girls without asthma than boys had quit smoking (OR: 1.47; 95\% CI: 1.18-1.85).

CONCLUSIONS: For girls, having asthma did not prevent them from smoking; but for boys, it did prevent them from smoking. Despite recommendations to stop smoking and limit ETS exposure for persons with asthma, it remains a significant public health issue among British Columbian adolescents, particular girls.

Financial Support: This research was supported by the Centre for Additions Research of BC and funded by a Canadian Institutes of Health Research operating grant.

\section{5}

HOW SHOULD NASAL NITRIC OXIDE BE MEASURED TO
SCREEN FOR PRIMARY CILIARY DYSKINESIA IN CHILDREN? D Mateos-Corral, R Coombs, H Grasemann, F Ratjen, SD Dell Respiratory Medicine Department, Hospital for Sick Children, University of Toronto, Toronto, Ontario

RATIONALE: Nasal nitric oxide (NNO) is considered a reliable non-invasive screening test for Primary Ciliary Dyskinesia (PCD) but 
measuring techniques are not standardized in children. Developing reliable and valid non-invasive breathing techniques that require minimal cooperation will allow us to extend NNO screening to infancy.

OBJECTIVE: Our goal is to test five breathing techniques during NNO screening. The two main objectives of this project are: 1 . Determine which breathing technique has the best ability to discriminate between different patient groups. 2. Determine if tidal breathing techniques, which would be directly applicable to infants, have discriminative utility in screening children for PCD.

METHODS: Using Echo physics quemioluminicence NO analyzer 5 breathing techniques were tested. Breath hold $(\mathrm{BH})$, exhaled resistance (ER), tidal breathing mouth open (TBMO) \& mouth close (TBMC) and humming (HUM). Four different patient groups were recruited from our clinics. PCD, Cystic Fibrosis (CF), non-PCD/CF bronchiectasis (B) and healthy controls.

RESULTS: To date, we have recruited a total $n=91: \operatorname{PCD} n=26$, CF $n=32$, $B n=14$, controls $n=19$. All breathing techniques yield statistically significant differences in NNO between PCD and control groups (tested using ANOVA, $\mathrm{p}$-value $<0.05$ ). Magnitude of NNO: $\mathrm{HUM}>\mathrm{ER}>\mathrm{BH}>\mathrm{TBMO}>$ TBMC as expected. ER ensures velum closure and thus gives reproducible NNO measurement. TBMC is most susceptible to dilutional contamination with lower airways nitric oxide.

CONCLUSIONS: ER technique is the most reliable in cooperative children. Tidal breathing manoeuvres can discriminate PCD children from controls. Sensitivity and specificity cut off values will be developed once full sample size is recruited.

\section{6}

\section{CARESS: THE CANADIAN REGISTRY OF SYNAGIS ${ }^{\circledR}$}

I Mitchell ${ }^{1}$, E Reim ${ }^{2}$, K Lanctot ${ }^{2}$, B Paes ${ }^{3}$

${ }^{1}$ Alberta Children's Hospital, University of Calgary, Calgary, Alberta; ${ }^{2}$ MORE Research Group, Sunnybrook Health Sciences Centre, Toronto; ${ }^{3}$ McMaster University, Hamilton, Ontario OBJECTIVE: To understand current management (utilization, compliance) with palivizumab prophylaxis of children at high-risk of RSV infection in Canada.

METHODS: A prospective, observational, registry of infants at high risk for RSV who received at least 1 dose of palivizumab during the 2006 to 2008 RSV seasons from 24 sites. Neonatal and demographic data were collected upon enrollment. Data on palivizumab utilization and compliance, including outcomes related to a respiratory infection were collected monthly until the full course of palivizumab was completed or at the end of the relevant RSV season.

RESULTS: 2910 infants were enrolled, age 2 days to 47 months (mean = 5.5 months). $54.4 \%$ male, $62.2 \%$ Caucasian, average gestational age (GA) was $32.0 \pm 6.8$ completed weeks. $2079(71.4 \%)$ infants received palivizumab because they were premature only (i.e. $\leq 35$ completed weeks GA), $255(8.8 \%)$ required oxygen, $288(9.9 \%)$ had congenital heart disease and 288 (9.9\%) were prophylaxed for other risk factors such as CNS disorders, airway anomalies and cystic fibrosis. Compliance was high; $77.8 \%$ received at least 4 injections of palivizumab between September and June each season. Overall 12,973 doses were given. No directly related serious adverse events were identified.

159 infants had 194 hospitalizations for respiratory tract infections, a hospitalization rate of $5.5 \%$. RSV positive hospitalization declined from $1.4 \%$ in $2006-07$ to $0.8 \%$ in $2007-08$ and was $0.96 \%$ overall. Hospitalization rates were highest with chronic lung disease $(9.8 \%, \mathrm{p}=0.006)$, and in nonCaucasians of Hispanic (12.5\%) or aboriginal descents $(7.9 \%, \mathrm{~ns})$.

CONCLUSIONS: The RSV hospitalization rate observed in the 2006 to 2008 RSV seasons was lower than in published reports. This likely confirms effectiveness of palivizumab but the rate may also be decreasing because of high compliance with palivizumab prophylaxis, and variability in RSV epidemiology and admission criteria.

Financial Support: Unrestricted grant from Abbott Canada.
37

\section{A NOVEL ROLE FOR SP-D: IT ENHANCES APOPTOSIS AND RELEASE OF V-SAP OR MICROPARTICLES FROM APOPTOTIC CELLS}

Pascal Djiadeu, Nicole Farmakovski, Lorena Polo, Nades Palaniyar

Lung Innate Immunity Research, Program in Physiology and

Experimental Medicine, SickKids; Department of Laboratory

Medicine and Pathobiology, Faculty of Medicine, University of

Toronto, Toronto, Ontario

RATIONALE: The accumulation of dying immune cells induces inflammation and disrupts tissue homeostasis in many lung diseases including asthma and COPD. Therefore, effective removal of these cells and their particles is crucial. We, and others, have previously shown that the innate immune collectin surfactant protein D (SP-D) binds dying cells and enhances their clearance, in vivo. Our previous studies showed that the absence of SP-D results in the accumulation of dead immune cells in mouse lungs. However, how SP-D exerts its function in this context is unknown. We hypothesized that SP-D facilitates the death of immune cells and/or enhances their clearance by macrophages.

METHODS: To determine the effect of SP-D on program cell death, or apoptosis, we induced cell death by UV irradiation and examined the apoptotic (apo) cells and the release of apoptotic particles from these cells in the presence or absence of SP-D, in vitro. We analyzed these cells by differential centrifugation, fluorescence/confocal microscopy and DNA laddering. We conducted apo cell uptake experiments using J774 murine macrophages.

RESULTS: Our results show that apo cells release vesicle-like small apoptotic micro particles, or v-SAPs. Notably, these particles are different from the commonly known apoptotic bodies or blebs. Co-localization experiments suggest that SP-D is located near highly polymerized actin where v-SAPs are attached/released from the cells. SP-D accelerates DNA condensation, TUNEL-positive DNA blebs formation and DNA laddering in these cells. We also found that the presence of SP-D leads to increased release of blebs and v-SAPs from these dying cells, and uptake of these particles by macrophages.

CONCLUSIONS: SP-D increases both the formation/release of blebs and $\mathrm{v}$-SAPs, and the clearance of these particles by macrophages. Therefore, we propose that SP-D helps to clear apoptotic cells effectively in the form of $\mathrm{v}$-SAPs from the lungs and downregulate inflammation.

Financial Support: SickKids Foundation and CIHR operating grants to NP.

\section{8}

\section{A COMPARISON OF MORTALITY TRENDS IN SCHOOL- AGED CHILDREN WITH AND WITHOUT ASTHMA}

Dhenuka Radhakrishnan ${ }^{1,2}$, Jun Guan ${ }^{3}$, Chengning Wang1, Andrea Gershon ${ }^{1,2,3}$, Sharon Dell ${ }^{1,2}$, Teresa To ${ }^{1,2,3}$

${ }^{1}$ Hospital For Sick Children; ${ }^{2}$ University of Toronto; ${ }^{3}$ Institute for Clinical Evaluative Sciences, Toronto, Ontario

RATIONALE: In the last decade there have been significant advances in asthma management. Recent studies suggest that mortality due to asthma may be decreasing. We aimed to determine whether the mortality pattern in children with asthma has improved compared to those without asthma. METHODS: A population-based study was conducted using the health administrative data of all school-aged children (5-19 years) living in Ontario, Canada. Children aged 0-4 years were excluded given the difficulty in diagnosing asthma in this age group. Age and sex adjusted mortality rates per 100,000 were calculated from 1996 to 2006 in children with and without asthma. Standardized mortality rate ratios were calculated with $95 \%$ confidence intervals $(\mathrm{CI})$.

RESULTS: The standardized mortality rates were higher in children with asthma compared to those without. In 2006, the rates were 24.5 and 18.7 per 100,000 respectively, representing a ratio of 1.31 (95\% CI: 1.07, 1.59). Similar ratios were observed throughout the 11 years studied. 


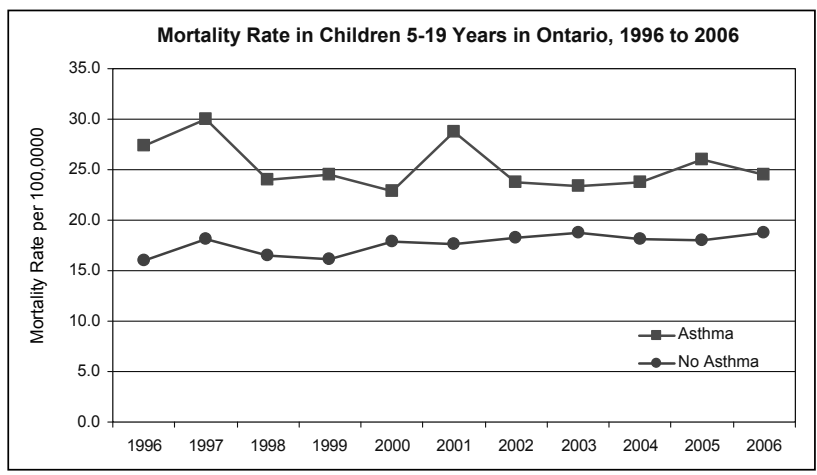

CONCLUSIONS: The mortality rates in school-aged children have remained stable in Ontario since 1996. Despite improvements in healthcare for children with asthma, they continue to show substantially higher mortality rates than children without asthma. More research is needed to prevent premature deaths in this population.

Financial Support: The Hospital for Sick Children, Restracomp Fellowship Award.

\section{9}

\section{DOES LOWER SES PREDICT INCREASED EXPOSURE TO}

ENVIRONMENTAL ASTHMA TRIGGERS IN CHILDREN?

Dhenuka Radhakrishnan $^{1,2}$, Teresa To ${ }^{1,2,3}$, Richard Foty ${ }^{1}$, Sharon Dell ${ }^{1,2}$

${ }^{1}$ The Hospital for Sick Children; ${ }^{2}$ The University of Toronto;

${ }^{3}$ Institute for Clinical Evaluative Sciences, Toronto, Ontario

RATIONALE: Low socioeconomic status (SES) is known to be associated with higher asthma severity. The specific reasons for this finding have not been well elucidated. We aimed to identify the association between known asthma triggers and SES in children.

METHODS: Data on all children with current asthma was extracted from a population-based health survey of 5619 Toronto school children (aged $5-9$ years) conducted in 2006. SES was defined by income adequacy (IA; calculated using a validated algorithm comparing household income to number of persons living in the household). Logistic regression was used to compare the rate of exposure to environmental tobacco smoke (ETS), pets, cockroach, household mold, gas heating or cooking, and carpeting between the highest and lowest IA quartiles.

RESULTS: Children in the lowest IA quartile had the highest rate of exposure to ETS $(20.6 \%$ vs $11.1 \%, \mathrm{OR}=2.1,95 \%$ CI $1.1-3.9)$ and cockroaches $(40.6 \%$ vs $0.9 \%, \mathrm{OR}=73.2,95 \% \mathrm{CI} 17.2-312.3)$ while children in the highest IA quartile had the highest rate of exposure to pets in the home (36.8\% vs $9.4 \%, \mathrm{OR}=5.1,95 \%$ CI $2.5-10.4$ ), gas cooking or heating $(\mathrm{OR}=10.4,95 \% \mathrm{CI} 5.7-19.0)$ and carpeting $(50.0 \%$ vs $34.3 \%, \mathrm{OR}=1.9$, 95\% CI 1.2-3.2).

CONCLUSIONS: Children from the highest and lowest SES quartiles in Toronto have significantly different rates of exposure to many well-known asthma triggers. Coming from a higher SES does not protect against exposure to all asthma triggers. Future research will allow determination of the relationship between SES, exposure to asthma triggers and severity of asthma in children.

Financial Support: Health Canada. 


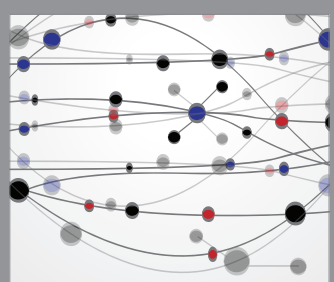

The Scientific World Journal
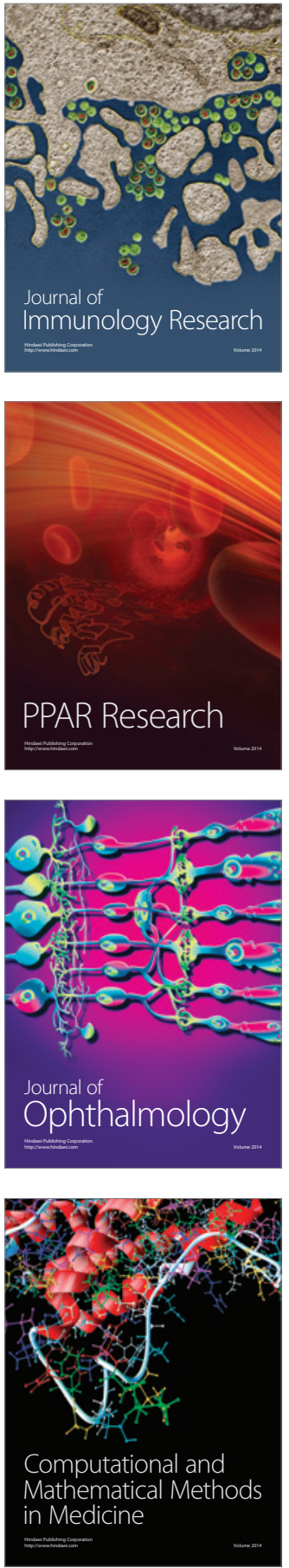

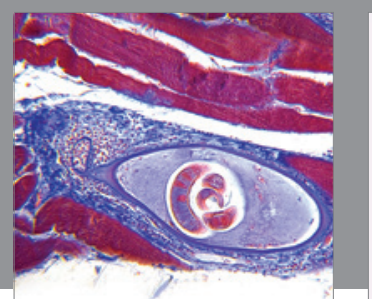

Gastroenterology Research and Practice

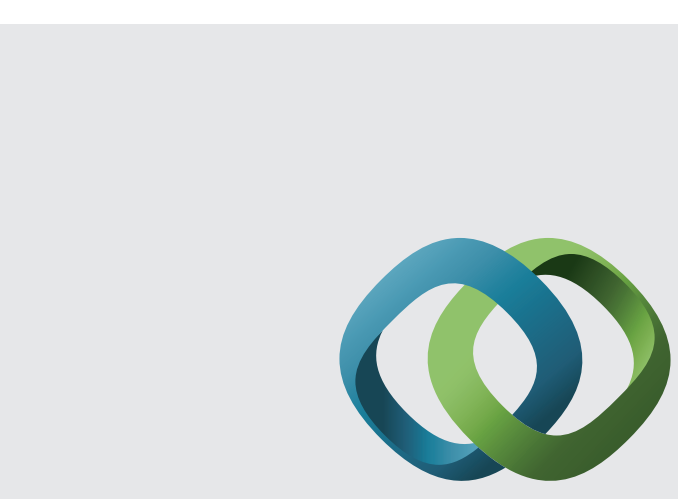

\section{Hindawi}

Submit your manuscripts at

http://www.hindawi.com
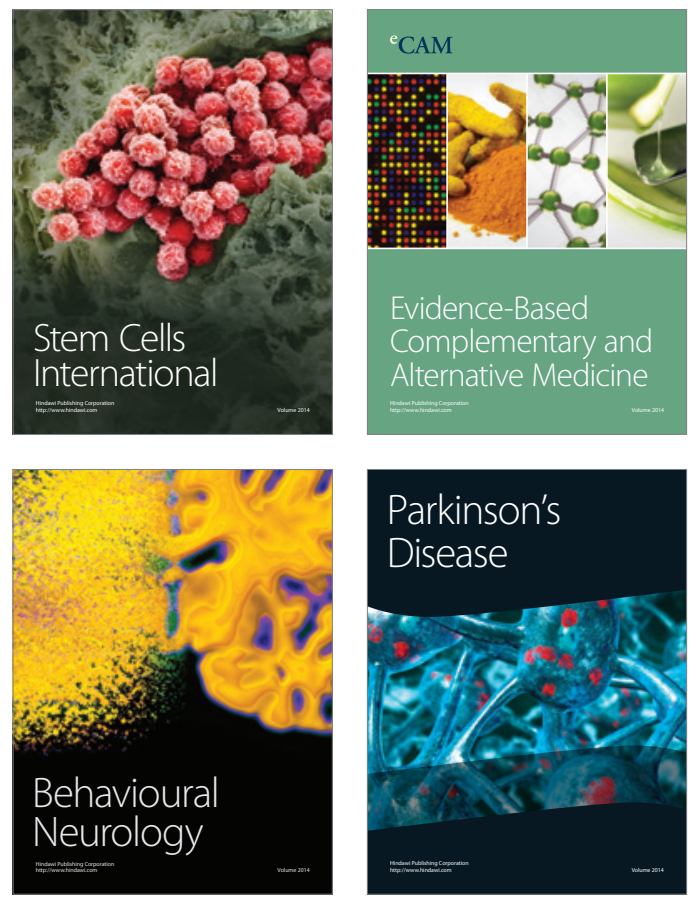
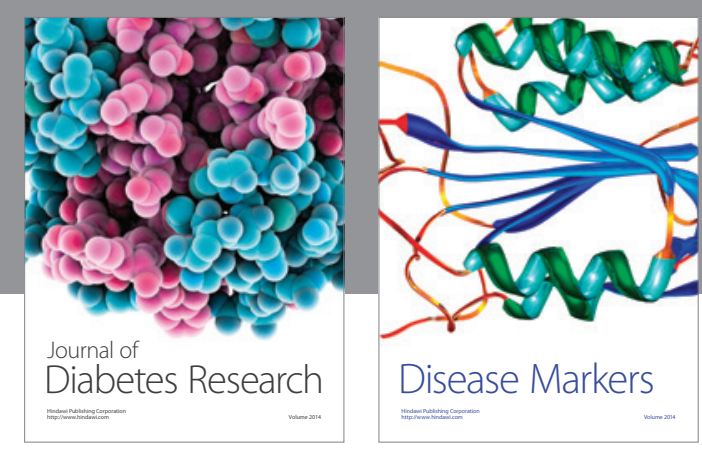

Disease Markers
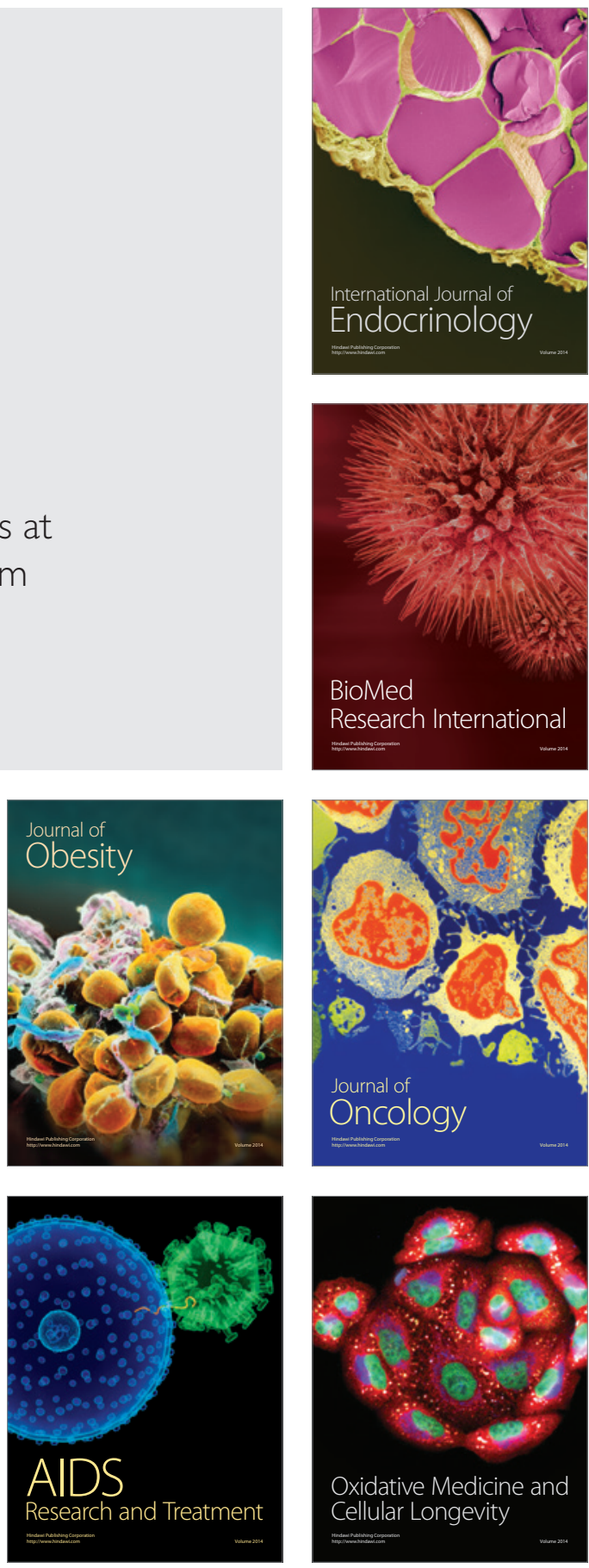